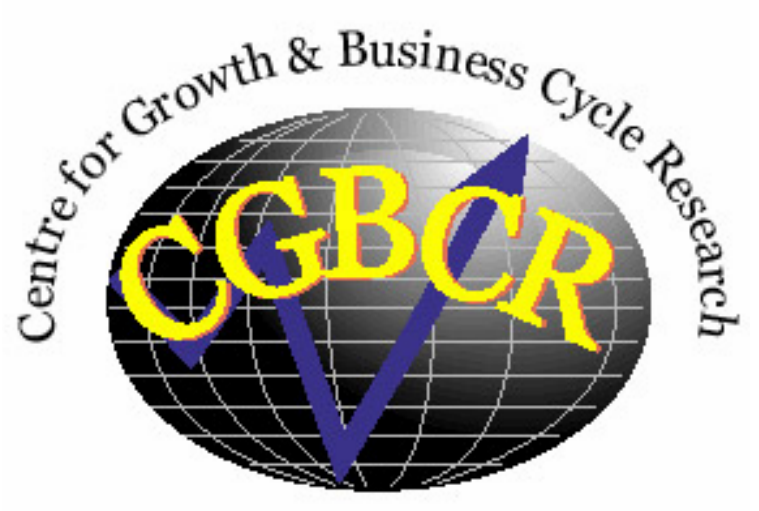

Discussion Paper Series

\title{
Balanced growth and the great ratios: new evidence for the US and UK By
}

\section{Cliff L. F. Attfield and Jonathan R. W. Temple}

Centre for Growth and Business Cycle Research, Economic Studies,

University of Manchester, Manchester, M13 9PL, UK

September 2006

Number 074

Download paper from:

http://www.ses.man.ac.uk/cgbcr/discussi.htm 


\title{
Balanced growth and the great ratios: new evidence for the US and UK*
}

\author{
Cliff L. F. Attfield \\ Emeritus Professor, Department of Economics \\ University of Bristol, 8 Woodland Road, Bristol BS8 1TN \\ Jonathan R. W. Temple ${ }^{\dagger}$ \\ Department of Economics, University of Bristol \\ 8 Woodland Road, Bristol BS8 1 TN and CEPR
}

September 14, 2006

\begin{abstract}
Standard macroeconomic models suggest that the 'great ratios' of consumption to output and investment to output should be stable functions of structural parameters. We examine whether the ratios are stationary for the US and UK, allowing for structural breaks that could reflect timevarying parameters. We find stronger evidence for stationarity than previous work. We then use the long-run restrictions associated with the stationarity of the great ratios to extract measures of trend output from the joint behaviour of consumption, investment and output. This approach is attractive because it uses information from several series without requiring restrictive assumptions.

Keywords: Great ratios, structural breaks, permanent components, trend output.

JEL Classifications: C32, E20, E30
\end{abstract}

\footnotetext{
${ }^{*}$ The research in this paper was funded by ESRC award number R000223760. We are grateful to David Demery, Morten Ravn, seminar participants at the University of Bristol and the Money, Macro and Finance conference at the University of Cambridge, and especially Chris Bowdler for helpful comments and advice. The usual disclaimer shields them all.

${ }^{\dagger}$ Corresponding author. Email jon.temple@bristol.ac.uk Telephone +44 1179288430 . Fax +44 1179288577 .
} 


\section{Introduction}

As is well known, applied work in macroeconometrics faces a significant tradeoff. The specification and interpretation of empirical models should be guided by economic theory. But if too many model-specific assumptions are used, there is a danger that the final estimates are misleading, because a stylized or inadequate model has been forced upon the data.

One of the most important responses to this problem has been to focus on theoretical predictions that are general to wide classes of models. These are often predictions about long-run outcomes, since models that differ sharply in their short-run predictions will often be in much closer agreement about the nature of a long-run equilibrium. Observations like this have motivated important studies, such as Blanchard and Quah (1989), Galí (1999), King et al. (1991), and Shapiro and Watson (1988) that identify macroeconomic shocks using longrun restrictions. Since these restrictions are common to a range of models, they can be used to guide identification and interpretation under relatively general assumptions, without the need for a full structural model.

Some relevant long-run predictions arise directly from models of economic growth. Whether growth is viewed as exogenous or endogenous, standard models give rise to a balanced growth path with a trendless real interest rate and a constant capital-output ratio. Economies are hence viewed as converging towards an equilibrium path in which capital and output grow at the same rate. The "great ratios" of investment to output, and consumption to output, will also be constant along the balanced growth path.

In an important paper, King et al. (1991), henceforth KPSW, explored these long-run predictions in the context of stochastic growth. Their starting point is that, along a balanced growth path, economic theory predicts that the equilibrium great ratios should be stable functions of structural parameters. To the extent that these parameters are time-invariant, and that economies are genuinely fluctuating around a balanced growth path, we should then expect the great ratios to be stationary processes. In turn, this implies that log consumption and log investment should each be cointegrated with log output, with unit cointegrating vectors.

KPSW could not reject this prediction. They showed how the associated long-run restrictions could be used to identify various kinds of macroeconomic shocks. In a less widely-noted contribution, KPSW also pointed out that the same restrictions could be used to extract measures of trend output that draw on the joint behaviour of consumption, investment and output, while imposing relatively little theoretical structure. 
Not surprisingly, given these wide-ranging implications, the KPSW approach has been influential. Yet subsequent empirical work has not always been so kind to the hypothesis that the great ratios are stationary. This has sometimes been used as evidence against exogenous growth models, but this is unsatisfactory, because balanced growth paths are found in a much wider range of models. We argue that an alternative perspective is more interesting. Since the equilibrium great ratios depend on structural parameters, it is clear that the ratios could display mean shifts over time. In other words, tests for stationarity of the great ratios are ultimately testing a joint hypothesis: not only convergence towards a balanced growth path, but also the auxiliary assumption of parameter constancy.

Our paper draws on this idea to make several contributions to the literature. The first task of the paper is to examine the stationarity prediction for the US and the UK, using a longer span of data than previous work, and proceeding under more general assumptions. We estimate a VECM for the US between 1955 and 2002, and for the UK between 1955 and 2001. An important departure from previous work, which is partly motivated by the adoption of chain-weighting for real aggregates in the US National Income and Product Accounts, is that we examine the great ratios in terms of current prices rather than constant prices. The importance of looking at investment shares in terms of current prices has been made by various authors, including Parente and Prescott (2000, p.44), but has rarely been taken into account in previous empirical analysis of the great ratios. This is surprising, because the ratios in current prices will be stationary under more general conditions than ratios of real quantities. We will discuss these issues in more detail in section 2 below.

Another improvement over previous research is that, in studying the KPSW hypothesis, we explicitly allow for structural breaks in the equilibrium ratios. As we will see in section 3 of the paper, this is a possibility that theory cannot rule out. Once we allow for up to two structural breaks, there is evidence for the two cointegrating vectors predicted by the theory, using both the multivariate Johansen procedure and single-equation tests. This evidence is stronger than in several previous papers. Moreover, these results are robust to the precise choice of break dates. The evidence for unit coefficients in the cointegrating vectors is weaker, but the departures from unity are not large in economic terms.

Having established some evidence for stationarity, we then develop the second task of the paper. This is to extend the multivariate approach to trend measurement that KPSW introduced, using ideas that we describe in section 4. If the great ratios are stationary, this can be used to combine information from different series in estimating the permanent component in output. This 
contrasts with the more conventional univariate approach, in which output is separated into permanent and temporary components using only the information in the output series itself. This seems unnecessarily restrictive, and there has been some interest in methods which utilise more information. For example, to the extent that consumers are forward-looking and follow the permanent income hypothesis, movements in consumption may be informative about the position of output relative to trend. ${ }^{1}$ If output falls, but consumption does not, this suggests that the fall in output has been perceived as transitory rather than permanent. In general, consumers may often be aware of information relevant to economic prospects that is not directly available to the econometrician, nor fully reflected in the past history of output.

The remaining question is precisely how to use the joint behavior of consumption, investment and output to measure trends, without making strong and highly model-specific assumptions. KPSW showed how this could be done, when the stationarity of the great ratios is not rejected by the data. The longrun restrictions associated with stationary great ratios immediately provide a way of inferring a common permanent component. More precisely, the KPSW strategy was to estimate a VECM and then extract the permanent component in output using a multivariate version of the Beveridge-Nelson (1981) decomposition, hereafter BN. ${ }^{2}$ As recommended by Garratt et al. (2006), the multivariate permanent-temporary decomposition is based on those underlying processes that are identified as stationary by economic theory, here the great ratios.

One way in which we improve upon the KPSW approach is to use more general permanent-temporary decompositions, based on the work of Gonzalo and Granger (1995) and Proietti (1997). We also extend the KPSW approach in a second direction, motivated by the empirical analysis earlier in the paper. If there are structural breaks in the underlying stationary processes, multivariate permanent-temporary decompositions have to be modified to allow for this. We show how this can be done in section 4 , and implement the approach in section 7 .

The rest of the paper has the following structure. In section 2, we discuss the existing literature and related measurement issues. Section 3 explores the sensitivity of the equilibrium great ratios to variation in structural parameters. Section 4 briefly describes the new econometric results that we need to carry out multivariate decompositions in the presence of structural breaks. Our empirical results are then presented in the heart of the paper, sections 5, 6 and 7. Section 5

\footnotetext{
${ }^{1}$ Cochrane (1994), Cogley (2005) and Fisher et al. (2003) have all emphasized this point.

${ }^{2}$ Related ideas can be found in work by Cochrane (1994) and Fama (1992). Also note that for their reported trend/cycle decomposition, KPSW use a six variable system (p. 837).
} 
reports the strong evidence for structural breaks, section 6 reports our estimates of the cointegrating vectors, and section 7 presents examples of multivariate estimates of trend output. Section 8 provides some additional discussion and a summary.

\section{Relation to existing literature}

Analysis of the long-term movements in the great ratios is usually based on the neoclassical growth model. Within this model, if technical progress is strictly labour-augmenting and occurs at a constant rate, there will usually be a balanced growth path along which output, consumption, capital, and investment all grow at the same constant rate. This implies that the great ratios of consumption to output, and investment to output, are constant in the steady state.

This is perhaps not surprising, since the steady state of a growth model can be thought of as an outcome that can be sustained indefinitely. It follows from a closed economy's aggregate resource constraint $(Y=C+I)$ that, if investment and consumption are always positive, then consumption and investment can only grow at constant rates indefinitely if they both grow at the same rate as output. Much the same reasoning explains why some models of endogenous growth also deliver a balanced growth path.

As KPSW pointed out, this property of deterministic models has a natural analogue in models where technical progress is stochastic. When there is a stochastic steady state, the great ratios will be stationary stochastic processes. Certain models of stochastic endogenous growth also imply stationarity of the great ratios, as in the version of Romer (1986) analyzed by Lau and Sin (1997). More generally, the stochastic endogenous growth model introduced by Eaton (1981) also admits an equilibrium in which all real quantities grow at the same stochastic rate.

The conclusion that the great ratios should be stationary appears fairly general, and appears to have useful empirical implications. The associated long-run restrictions are common to a large class of models, and impose some theoretical structure without being unduly restrictive. Structural VAR modelling based on weak long-run restrictions is often regarded as a promising research strategy, as for example in Soderlind and Vredin (1996).

The generality of the restrictions raises a puzzle, however. In the work that has followed KPSW, researchers have studied countries other than the US, and have found that stationarity of the great ratios is frequently rejected. Sometimes, non-stationarity of the great ratios is used as evidence against models of 
exogenous growth, as in the work of Serletis $(1994,1996)$ on Canadian data and Serletis and Krichel (1995) for ten OECD countries. But as we have seen, and will discuss further below, the prediction of stationarity is common to a much wider range of growth models.

Overall, the evidence for stationarity is mixed. In the case of the US, using data until 1998, Evans (2000) finds that the net investment ratio is stationary, but the gross investment ratio is only trend stationary, reflecting trends in depreciation. Fisher et al. (2003), using US data for 1948 to 2000, find stronger evidence of two cointegrating vectors, although the normalized coefficients on output depart slightly from unity. D'Adda and Scorcu (2003) examine the stationarity of the capital-output ratio over long time spans for a selection of industrialized countries. They find that the capital-output ratio is stationary for the US, but not for Japan. For the UK, they find evidence for stationarity over 1870-1948, but not over the longer period 1870-1992. Kim et al. (forthcoming) find evidence for the US that real non-durables consumption and GNP are cointegrated, when the cointegrating vector is imposed.

The possible lack of stationarity can be seen in figures 1 and 2, which plot the logs of the great ratios for the US and UK from 1955 onwards (we discuss the data sources in more detail later). In each figure, the upper line is the log consumption ratio, and the lower line the log investment ratio. ${ }^{3}$ The dotted line is the log ratio for each quarter, while the dark line is a centred 10-year moving average. These moving averages clearly indicate long swings in the ratios over many years, and indicate that mean reversion is only occurring slowly, if at all. For both the US and the UK, there is an upwards trend in the consumption ratio in the 1980 s.

Why does mean reversion appear to be so slow? As discussed above, we address this puzzle by arguing that the great ratios are likely to be subject to periodic mean shifts, or structural breaks. Our view of the ratios is that, even if the majority of shocks to them are temporary, there may be occasional permanent shocks that reflect changes in underlying parameters. We will discuss this in more detail in the next section of the paper. There, we show that a plausible extent of variation in structural parameters could give rise to quantitatively significant changes in the equilibrium values of the great ratios.

This suggests that testing for stationarity has to allow for occasional structural breaks, and a key element of our empirical work is to allow for occasional

\footnotetext{
${ }^{3}$ The log investment ratio is more volatile because reallocating one percentage point of GDP from consumption to investment has a greater proportional effect on the investment ratio, given that investment accounts for a much smaller share of GDP than consumption.
} 
mean shifts in the great ratios. ${ }^{4}$ It is worth emphasizing that there are at least two other possible responses to the apparent non-stationarity of the great ratios, however. One would be to argue that the great ratios follow a long-memory process. Another response would be to allow for significant non-linearities, as in the macroeconometric literature on regime-switching models. ${ }^{5}$ Either of these responses is clearly defensible, but each has drawbacks, and we think it is also worth experimenting with the simpler approach that we adopt here. Even on conceptual grounds, it is not clear that introducing regime-switching is a better way to study the great ratios than introducing a small number of discrete breaks.

A related alternative to our tests for structural breaks would be to estimate models in which the equilibrium great ratios are a specific function of observables, as in some of the empirical work in KPSW and in Ahmed and Rogers (2000). In principle, this would have some advantages. When estimating a more specific model, the VECM could be less likely to undergo structural breaks that are unknown in source. In practice, however, there is considerable uncertainty about the most important determinants of the equilibrium great ratios, the relevant functional forms, and also about whether the associated relationships will be stable over time. As noted by Erceg et al. (2005), the use of long-run restrictions is often appealing precisely because there is no need for a fully-articulated structural model or numerous model-specific assumptions. It is therefore interesting to ask whether the stationarity of the great ratios can be established under minimal assumptions, and that is the approach we take in this paper.

In the remainder of this section, we review the measurement issue that was briefly raised in the introduction, to motivate our focus on the ratios measured in current prices. The distinction between current-price and constant price-ratios has become especially important since the recent introduction of chain-weighted quantity and price indices in the National Income and Product Accounts (Whelan 2002). When real quantities are chain aggregates, the components of GDP can have unfamiliar properties. In particular, real GDP is no longer the standard sum of real components: in simple terms $\mathrm{Y}$ does not equal $\mathrm{C}+\mathrm{I}+\mathrm{G}+\mathrm{X}-\mathrm{M}$ when all real variables are measured as chain-weighted index numbers. This is because real output is no longer defined as the sum of the expenditure compo-

\footnotetext{
${ }^{4}$ For example, after taking structural breaks into account, Cook (2005) finds much stronger evidence that the ratio of consumption to income is stationary, for 20 OECD economies observed over 1955-1994. See also Clemente et al. (1999).

${ }^{5}$ For example, Nelson et al. (2001) show that unit root tests can have low power against alternatives with a Markov-switching trend. Paap and van Dijk (2003) and Kim et al. (forthcoming) analyze the consumption-income relationship using Markov-switching ideas. Note that it may be hard to discriminate empirically between Markov-switching models and long memory; see Diebold and Inoue (2001).
} 
nents all evaluated at a constant set of relative prices. The lack of additivity is a consequence of using the chain-weighted growth rates of the series to construct measures of levels. ${ }^{6}$

The difference between a chain quantity aggregate and the more familiar fixed-weight aggregate emerges when relative prices are changing. This can raise problems for analysing the great ratios in what appear to be real terms. Moreover, when relative prices are changing, it is not clear how one should interpret the ratio between a series like real consumption and real output, or whether these "real shares" are economically meaningful, even when fixed-weight methods are used. Although the concepts "real consumption" and "real output" have obvious economic interpretations, this is much less clear of their ratio (see Whelan 2002, especially p. 226-228). It is not clear why we should focus on what the share of consumption in output would have been, if relative prices had remained at those of a given base year. As Whelan shows, the choice of base year can make enormous differences to the calculated real shares. This in itself suggests that caution is needed before attempting to analyze the great ratios in constant-price terms.

But the idea that relations among macroeconomic series should be analyzed in terms of real quantities looks like common sense. This view arises largely from the study of one-sector models, in which there is no role for changing relative prices (for example, of capital goods). In a world with only one form of output, there is no substantive distinction between the nominal investment share and the ratio of real investment to real GDP. In a two-sector world, in which the relative price of capital goods can change, the distinction matters. The great ratios need not be stationary when expressed in real terms, as noted in Parente and Prescott (2000, p. 44). ${ }^{7}$

With this in mind, and motivated by recent growth models, we will focus on stationarity in the nominal (current-price) ratios. The key point is that the nominal ratios are stationary under more general conditions than the constant-price ratios. This is because the constant-price ratios are unlikely to be stationary in any model with more than one sector. For example, the two-sector model of Greenwood et al. (1997) has the property that nominal consumption and nominal investment grow at the same rate as nominal output along a balanced

\footnotetext{
${ }^{6}$ Whelan (2002) provides a useful summary of the justification for the chaining procedure, and its implications for empirical work, including the resulting lack of additivity of expenditure components. Note that chain-weighted indices are also being introduced in the UK National Accounts.

${ }^{7}$ Consider a simple example in which a constant share of nominal GDP is invested in each period. If the relative price of capital goods is declining, real investment grows more quickly than real consumption.
} 
growth path. Since the relative price of capital is changing along this growth path, the ratios of real quantities will not be constant. Models in Parente and Prescott (2000) and Whelan (2003) share the same property. We therefore base our empirical work on the ratios of investment to output, and consumption to output, measured in current prices rather than constant prices.

The decision to focus on the nominal ratios has another convenient implication: we no longer need to worry about the lack of additivity in the chainweighted real aggregates. For example, when using nominal series, we can construct a measure of nominal private sector output by simply subtracting nominal government purchases from nominal output. This would not be possible when working with the variables in real terms, because real variables constructed using chain-weighted indices cannot simply be added or subtracted in this way, but have to be reaggregated from their separate components (Whelan 2002).

There is one remaining problem with the use of nominal series. In the case where the inflation rate is $\mathrm{I}(1)$, this implies that the log of the price level is $\mathrm{I}(2)$. The nominal series for the logarithms of output, consumption and investment would then inherit this I(2) property. To avoid this problem, our empirical analysis will follow Greenwood et al. (1997, p. 347) in deflating all the nominal series by the same consumption-based price deflator. Our approach is also consistent with points made independently by Palumbo et al. (2006, p.10) in their study of the macroeconomic relationships between consumption, income and wealth. They summarize their basic message in the following terms: "[macroeconomic] variables that are linked by a budget constraint must be transformed into real equivalents in a manner that respects and preserves the budget constraint's underlying nominal relationship (e.g. by deflating both sides of the constraint with the same price index)". That is exactly the approach taken here.

\section{Theoretical considerations}

In this section, we use a simple growth model to illustrate the dependence of the great ratios on structural parameters. These parameters are the rate of technical progress, the depreciation rate, the intertemporal elasticity of substitution, and the discount factor. We briefly document a few reasons to believe that some of these parameters have changed over time. Our analysis shows that changes in these parameters can have substantial effects on the great ratios, and could therefore lead to structural breaks and spurious rejections of stationarity. ${ }^{8}$ Natural extensions to the analysis, for example to consider the effects of

\footnotetext{
${ }^{8}$ As Cooley and Dwyer (1998) and Soderlind and Vredin (1996) indicate, changes in structural parameters will also have implications for the short-run dynamics. Investigation of this
} 
time-varying capital taxes, would only tend to reinforce this point.

The results are based on the classic analysis of the stochastic growth model due to King, Plosser and Rebelo (1988), henceforth KPR, and on the technical appendix to that paper (since published as King, Plosser and Rebelo 2002). Since the analysis is now standard, we introduce a simplified version of it only briefly, and then investigate the sensitivity of the great ratios to changes in the structural parameters. ${ }^{9}$ The aim is to support our overall claim that sizeable shifts in the equilibrium ratios are not necessarily unrealistic. The setup we adopt is perhaps the simplest interesting growth model in which the ratios are determined endogenously, but the balanced growth restrictions are general to a much wider class of models.

The model is one of many identical agents, who each supply one unit of labour inelastically. The representative agent seeks to maximise lifetime utility:

$$
\begin{aligned}
U & =\sum_{t=0}^{\infty} \beta^{t} \frac{C(t)^{1-\sigma}}{1-\sigma} \text { if } 0<\sigma<1 \text { or } \sigma>1 \\
& =\sum_{t=0}^{\infty} \beta^{t} \log C(t) \text { if } \sigma=1
\end{aligned}
$$

where the parameter $\sigma$ is the inverse of the intertemporal elasticity of substitution. We will later impose a restriction on $\beta$ to ensure that lifetime utility is finite.

The agents (or firms) each produce a single good using a constant returns to scale production function

$$
Y_{t}=F\left(K_{t}, X_{t} N_{t}\right)
$$

where $X_{t}$ is an index of labour-augmenting technical change that evolves over time according to

$$
X_{t+1}=\gamma X_{t}
$$

where $\gamma>1$. Hence the growth rate of the technology index is constant and given by $\gamma-1$. As is standard in long-run analyses of growth models, we are basing our investigation on the steady state of a deterministic model.

The single good can be consumed or invested, and the evolution of physical capital is given by

$$
K_{t+1}=(1-\delta) K_{t}+I_{t}
$$

where $\delta$ is the rate of depreciation. The aggregate resource constraint is

$$
C_{t}+I_{t} \leq Y_{t}
$$

point is beyond the scope of the current paper, however.

${ }^{9}$ See Parker (1999, p. 325-326) for a related analysis. He considers the determinants of the great ratios in a continuous time Ramsey model, but does not explicitly quantify the effects. 
Since all agents are identical, there is no intertemporal trade. Hence each agent maximises lifetime utility (1) subject to the infinite sequences of constraints implied by equations (2)-(4). Using the arguments in King, Plosser and Rebelo (2002) there will be a steady state growth path in which consumption, investment, capital and output all grow at the same rate as technology, namely $\gamma-1$.

It can also be shown that the real rate of return on capital, net of depreciation, is given by

$$
r=\frac{\gamma^{\sigma}}{\beta}-1
$$

We need to impose a restriction on $\beta$ to ensure that lifetime utility is finite, namely

$$
\beta \gamma^{1-\sigma}<1
$$

which implies that the real return on capital is higher than the long-run growth rate.

It can then be shown (as in equation A27 in King, Plosser and Rebelo 2002) that the ratio of gross investment to output is given by:

$$
s_{i}=\frac{[\gamma-(1-\delta)] \beta \gamma^{1-\sigma} \alpha}{\gamma-\beta \gamma^{1-\sigma}(1-\delta)}
$$

where the new parameter $\alpha$ denotes the share of capital income in total income. Given our assumptions, the gross investment ratio is exactly equal to the saving ratio, or one minus the ratio of consumption to output.

We will not discuss the role of the capital share $\alpha$ in detail. Along a balanced growth path, the capital share will be constant in the long run. In practice, capital shares display significant variation over time in some OECD countries, as pointed out by Blanchard (1997). But Bentolila and Saint-Paul (2003) show that the capital share has been relatively stable in the two countries we consider, the US and (especially) the UK. This long-run stability of the capital share could itself be seen as evidence for a balanced growth path, along which the capitaloutput ratio is constant. But this interpretation does not resolve the questions surrounding balanced growth paths, because capital shares will also be constant in the special case where the aggregate production function is Cobb-Douglas.

We now consider the implications of (6) for the great ratios. For simplicity, we specialize to a Cobb-Douglas production function, so that the capital share $\alpha$ can be treated as an exogenous structural parameter. ${ }^{10}$ The first point to

\footnotetext{
${ }^{10}$ Under more general assumptions, the great ratios will depend on additional parameters; for example, with a CES technology, the elasticity of substitution in production will play a role.
} 
note is that the investment ratio depends on the long-run growth rate $\gamma$ unless two conditions are met: logarithmic utility $(\sigma=1)$ and complete depreciation of capital within each period $(\delta=1)$. The second condition is clearly unrealistic, and so in general the investment ratio will be a function of the rate of technical progress. ${ }^{11}$ Any change in that rate, such as the productivity slowdown of the 1970s, has implications for the steady-state investment ratio.

The investment ratio also depends on the subjective discount factor $(\beta)$, the intertemporal elasticity of substitution $(1 / \sigma)$, and the depreciation rate $\delta$. Can we say anything about the direction of these effects? If utility is logarithmic $(\sigma=1)$ it is straightforward to show that the ratio is increasing in all three remaining parameters $\beta, \delta$ and $\gamma$. If utility is not logarithmic, the analysis is less straightforward, but analytical results are still possible. As before, differentiation indicates that the investment ratio is increasing in $\beta$ and $\delta .{ }^{12}$ The investment ratio is also increasing in the intertemporal elasticity of substitution $(1 / \sigma)$. On the other hand, the effect of the long-run growth rate $\gamma$ is ambiguous without further assumptions.

How large are these effects? To gain some insight into this question, we repeatedly plot the function (6) allowing two parameters to vary and holding the other three constant at default values. We base our default parameter values mainly on the work of KPR (their Table 1) and define our parameters in quarterly terms. The default value for $\gamma$ is 1.004 , implying an annual growth rate of $1.6 \%$. We set the discount factor $\beta$ to 0.99 which is broadly consistent with the values implicit in KPR's simulations, and implies sensible real returns to capital for most of the parameter combinations that we consider. We follow KPR in setting the capital share to 0.42 and the quarterly depreciation rate to 0.025 , where the latter implies annual depreciation of $10 \%$. Our default value for $\sigma$ is 2. Overall, evaluating equation (6) at these default parameter values implies an investment ratio of around $28 \%$.

First of all, we study the effects of the trend growth rate and the utility curvature parameter $\sigma$ on the investment ratio. To do this, we vary the annual growth rate between $0 \%$ and $4 \%$, corresponding to values of the quarterly (gross) growth rate $\gamma$ between 1.00 and 1.01. We vary $\sigma$, the inverse of the elasticity of intertemporal substitution, between 0.001 and 5 . The results are shown in Figure 3. Importantly, the exercise reveals that the steady-state investment

\footnotetext{
${ }^{11}$ Our long-run solution of the model treats technical progress as deterministic. In our later empirical work, we will treat the trend in output as stochastic rather than deterministic. Even in stochastic models, however, the long-run investment-output ratio may be a stable function of structural parameters, as in the model of Abel (2003).

${ }^{12}$ Some of these results make use of the parameter restriction (5).
} 
ratio can be quite sensitive to the trend growth rate unless $\sigma$ is close to unity. The direction of the effect depends on the value of $\sigma$.

We carry out two similar exercises which replace the variation in the trend growth rate $\gamma$ with variation in either the discount factor $\beta$ or the depreciation rate $\delta$. These plots are shown as Figures 4 and 5 . In these figures, we again see that the investment ratio is sensitive to parameter changes, wiith the extent of the sensitivity influenced by the utility curvature parameter $\sigma$.

These plots all have a clear implication. Even if the majority of shocks to the great ratios are transitory, there is clearly some potential for changes in parameters to shift the great ratios, in such a way that they could appear non-stationary using standard tests. In the remainder of this section, we briefly discuss the potential for changes in the relevant parameters.

The case for quite substantial changes in the trend growth rate is clear. The 1970s saw a well-documented productivity slowdown across the developed world, with intermittent improvements in performance in the following decades. More formally, Ben-David and Papell (1998, 2000) and Benati (2006) have compiled statistical evidence of changes in long-term productivity growth rates. As Benati (2006) and many others have noted, the 1990s have seen faster trend growth in the US.

Less obviously, one could make a strong case for a change in the rate of depreciation. Evans (2000) points out that the depreciation rate implicit in the US National Income and Product Accounts has risen substantially over time, reflecting a change in the composition of the capital stock towards equipment and away from structures. Tevlin and Whelan (2003) also show that the composition of the capital stock is tending to shift towards assets with shorter service lives, as investment in equipment, particularly computers, assumes increasing importance. The analysis above indicates that a rise in the depreciation rate will tend to raise the equilibrium ratio of gross investment to output.

It is less conventional to make a case that the 'deep' parameters relating to preferences ( $\beta$ and $\sigma$ in this model) have changed. Even here, though, periodic shifts may be possible. Moving away from models of infinitely-lived representative agents, the constancy of these parameters appears less plausible in a world of overlapping generations, since different cohorts may not look exactly alike in their preferences. Although a parameter such as the discount factor may be roughly constant over a decade or more, we have less reason to assume this over the relatively long time span considered in this paper. Parker (1999) argues that a rise in the effective discount rate is a leading explanation for the decline in the US saving ratio after 1980 . 
In summary, even though theoretical models imply that the investmentoutput ratio will be mean reverting, the mean is likely to be subject to at least occasional shifts. Alternative models give rise to similar results. As an example, Abel (2003) constructs an overlapping generations model with a random birth rate, in which the long-run investment-output ratio is a stable function of structural parameters. In his model, these parameters include aspects of the social security system, which affect investment via saving. This shows how more complex models could reinforce the case for occasional mean shifts in the great ratios.

We briefly consider one final point in relation to the great ratios, and the relationship between the theoretical framework and empirical testing. In a closed economy, the gross investment ratio is essentially the mirror image of the ratio of consumption to output, and stationarity of one ratio necessarily implies stationarity of the other. In the data we use, however, household consumption and private sector investment do not sum to private sector output, mainly because of the current account. We therefore follow previous authors, including KPSW, in looking for stationarity in both ratios. The more ambitious task, of extending the KPSW framework to open economies, is left for further research. ${ }^{13}$

\section{Permanent-temporary decompositions}

In this section we describe the first part of the empirical strategy we adopt, namely permanent-temporary decompositions that incorporate the possibility of structural breaks in the cointegrating equations. These breaks have implications for the estimation of the VECM, and for the extraction of the permanent component from the estimated model. The permanent-temporary decompositions that we implement empirically use new results developed in Attfield (2003), and we briefly spell out the main details below.

As in KPSW we consider a three variable system based on consumption $C_{t}$, investment, $I_{t}$ and output, $Y_{t}$ (KPSW also consider larger systems). Let $c_{t}, i_{t}$ and $y_{t}$ be the natural logarithms of consumption, investment and output respectively, and let $x_{t}^{\prime}=\left(c_{t}, i_{t}, y_{t}\right)$. We will discuss the precise construction of these series in the next section.

We first consider the case without structural breaks. If $x_{t}$ is $I(1)$ then we can write the VECM as:

\footnotetext{
${ }^{13}$ For existing work along these lines, see DeLoach and Rasche (1998) and Mellander et al. (1992). Alternative long-run restrictions in open economies are considered by Garratt et al. (2003). Daniel (1997) uses the Johansen procedure to study international interdependence in productivity growth.
} 


$$
\triangle x_{t}=\theta_{o}+\theta_{1} \triangle x_{t-1}+\ldots+\theta_{k} \triangle x_{t-k}+\beta \alpha^{\prime} x_{t-1}+\zeta_{t}
$$

where $\triangle x_{t}=x_{t}-x_{t-1}, \zeta_{t}$ is a Gaussian error and $\alpha^{\prime}$ is the set of cointegrating vectors. There are $T$ observations in total.

If there are structural breaks in the mean of either the VECM or the cointegrating relations, then the specification in (7) is inappropriate. It will also be inappropriate if there are shifting trends in the cointegrating equations. ${ }^{14}$ To address this problem, suppose there are two breaks in the sample with $T_{1}$ observations in the first period, $T_{2}-T_{1}$ observations in the second period, and $T-T_{2}$ observations in the third period. Johansen et al. (2000) derive a likelihood ratio test for cointegration in the presence of breaks in trend and mean at known points, and that is the test we will implement below.

The VECM with structural breaks can be written as:

$$
\triangle x_{t}=\theta_{o} \bar{\Xi}_{t}+\sum_{j=1}^{k} \theta_{j} \triangle x_{t-j}+\beta\left(\alpha^{\prime}, \gamma^{\prime}\right)\left(\begin{array}{c}
x_{t-1} \\
t \Xi_{t}
\end{array}\right)+\sum_{i=1}^{k+1} \sum_{j=2}^{3} \kappa_{j i} D_{j t-i}+\zeta_{t}
$$

where $x_{t}=\left(c_{t}, y_{t}, i_{t}\right)^{\prime}, \theta_{o}=\left(\theta_{o 1}, \theta_{o 2}, \theta_{o 3}\right), D_{j t}=1$ for $t=T_{j-1}$, with $T_{o}=0$, and $D_{j t}=0$ otherwise and $\Xi_{t}^{\prime}=\left(\Xi_{1 t}^{\prime}, \Xi_{2 t}^{\prime}, \Xi_{3 t}^{\prime}\right)$ with $\Xi_{j t}=1$ for $T_{j-1}+k+2 \leq t \leq T_{j}$ and zero otherwise.

The $\Xi_{j t} s$ are dummies for the effective sample period for each sub-period. The $D_{j t-i} s$ have the effect of eliminating the first $k+1$ residuals of each period from the likelihood, thereby producing the conditional likelihood function given the initial values in each period. Hence this specification allows for shifts in the intercepts of both the VECM and the cointegrating equations, although such shifts cannot be identified individually. These intercept corrections are captured in the term $\theta_{o} \bar{\Xi}_{t}$. The model also allows for shifts in any time trends in the cointegrating equations, in the term $\gamma^{\prime} t \Xi_{t}$.

Once the model (8) has been estimated, we can extract estimates of the permanent component in the series using either the multivariate $\mathrm{BN}$ decomposition or the generalization of it due to Gonzalo and Granger (1995). As argued by Garratt, Robertson and Wright (2006), this general form of approach allows researchers to obtain permanent-temporary decompositions that are based on the stationary processes identified by economic theory. Moreover, some unattractive features of univariate decompositions, such as the tendency for highly volatile permanent components, are less likely to appear in multivariate decompositions.

\footnotetext{
${ }^{14}$ We exclude a linear time trend in the VECM as it would imply a quadratic trend in the levels of the variables.
} 
Our implementation of these decompositions requires some new results in order to incorporate structural breaks. The definition of the multivariate BN permanent components is:

$$
x_{t}^{B N-P}=x_{t}+\sum_{i=1}^{\infty} E_{t}\left(\Delta x_{t+i}-\mu_{\Delta x}\right)
$$

as in Cochrane (1994) for example. To determine a solution for (9), write the VECM in (8) as

$$
\Delta x_{t}=\mathcal{K}_{o} H_{t}+\sum_{j=1}^{k} \theta_{j} \Delta x_{t-j}+\beta v_{t-1}+\zeta_{t} .
$$

where $\mathcal{K}_{o}=\left(\theta_{o}, \varkappa\right)$ where $\varkappa$ contains the $\kappa_{j i}$ vectors, and:

$$
H_{t}=\left[\begin{array}{c}
\Xi_{t} \\
D_{1}
\end{array}\right]
$$

where $D_{1}$ contains the $D_{j t-i}$ dummies and $v_{t-1}=\alpha^{\prime} x_{t-1}+\gamma^{\prime} t \Xi_{t}$. It follows that:

$$
v_{t}=\alpha^{\prime} x_{t}+\gamma^{\prime}(t+1) \Xi_{t}=\alpha^{\prime} \Delta x_{t}+\gamma^{\prime} \Xi_{t}+v_{t-1}
$$

and then:

$$
v_{t}=\mathcal{K}_{o o} H_{t}+\alpha^{\prime} \theta_{1} \Delta x_{t-1}+\cdots+\alpha^{\prime} \theta_{k} \Delta x_{t-k}+\left(I+\alpha^{\prime} \beta\right) v_{t-1}+\alpha^{\prime} \zeta_{t}
$$

where:

$$
\mathcal{K}_{o o}=\left(\alpha^{\prime} \theta_{o}+\gamma^{\prime}, \alpha^{\prime} \varkappa\right) .
$$

Appending (11) to the system in (10) we have a first order stationary vector autoregression of the form:

$$
z_{t}=A_{o} H_{t}+A_{1} z_{t-1}+\Psi \zeta_{t} \quad t=1, \ldots, T
$$

where $z_{t}^{\prime}$ is the $(1 \times p k+r)$ vector:

$$
z_{t}^{\prime}=\left(\Delta x_{t}^{\prime}, \Delta x_{t-1}^{\prime}, \ldots, \Delta x_{t-k+1}^{\prime}, v_{t}^{\prime}\right)
$$

The matrices $A_{o}$ and $A_{1}$ are defined as:

$$
A_{o}=\left[\begin{array}{c}
\mathcal{K}_{o} \\
0 \\
0 \\
\vdots \\
0 \\
\mathcal{K}_{o o}
\end{array}\right]
$$


and:

$$
A_{1}=\left[\begin{array}{cccccc}
\theta_{1} & \theta_{2} & \cdots & \theta_{k-1} & \theta_{k} & \beta \\
I & 0 & \cdots & 0 & 0 & 0 \\
0 & I & \cdots & 0 & 0 & 0 \\
\vdots & \vdots & \cdots & \vdots & \vdots & \vdots \\
0 & 0 & \cdots & I & 0 & 0 \\
\alpha^{\prime} \theta_{1} & \alpha^{\prime} \theta_{2} & \cdots & \alpha^{\prime} \theta_{k-1} & \alpha^{\prime} \theta_{k} & \alpha^{\prime} \beta+I
\end{array}\right]
$$

and $\Psi$ is defined as:

$$
\Psi=\left[\begin{array}{c}
I \\
0 \\
\vdots \\
0 \\
\alpha^{\prime}
\end{array}\right]
$$

From (12) it follows that:

$$
E\left(z_{t}\right)=\mu_{z}=\left(I-A_{1}\right)^{-1} A_{o} H_{t}
$$

so that:

$$
z_{t}-\mu_{z}=\left(I-A_{1} L\right)^{-1} \Psi \zeta_{t}
$$

Define the matrix:

$$
G=\left[\begin{array}{c}
I_{p} \\
0 \\
\vdots \\
0
\end{array}\right]
$$

Then $G^{\prime} z_{t}$ selects out $\Delta x_{t}$ and it follows from (12) that:

$$
\Delta x_{t}-\mu_{\Delta x}=G^{\prime}\left(z_{t}-\mu_{z}\right)=G^{\prime}\left(I-A_{1} L\right)^{-1} \Psi \zeta_{t}=C(L) \zeta_{t}
$$

which is the moving average representation. Inverting $\left[I-A_{1}\right]$, it is straightforward to show that ${ }^{15}$ :

$$
C(1)=G^{\prime}\left[I-A_{1}\right]^{-1} \Psi=\theta(1)^{-1}-\theta(1)^{-1} \beta\left(\alpha^{\prime} \theta(1)^{-1} \beta\right)^{-1} \alpha^{\prime} \theta(1)^{-1}
$$

where $\theta(1)=I_{p}-\sum_{1}^{k} \theta_{i}$.

The expectations term in equation (9) can then be written as:

$$
\sum_{i=1}^{\infty} E_{t}\left(\Delta x_{t+i}-\mu_{\Delta x}\right)=G^{\prime} A_{1}\left[I-A_{1}\right]^{-1}\left(z_{t}-\mu_{z}\right) .
$$

\footnotetext{
${ }^{15}$ Proietti $[59,1997]$ obtains the same result using the Kalman filter except that instead of $\Theta(1)^{-1}$ he has $\left(\Theta(1)-\beta \alpha^{\prime}\right)^{-1}$. It is easy to show that the two forms give exactly the same $C(1)$.
} 
Some algebra (see Attfield 2003) produces:

$$
x_{t}^{B N-P}=C(1) \theta(L) x_{t}-Q \gamma^{\prime}(t+1) \Xi_{t}+\delta_{o}
$$

where $\theta(L)=I_{p}-\sum_{j=1}^{k} \theta_{j} L^{j} ; Q=\theta(1)^{-1} \beta\left(\alpha^{\prime} \theta(1)^{-1} \beta\right)^{-1}$; and $\delta_{o}=-C(1) \theta^{*}(1) \mu_{\Delta x}+$ $Q \mu_{v}$ with $\theta(L)=\theta(1)+(1-L) \theta^{*}(L)$ and where the population means $\mu_{\Delta x}$ and $\mu_{v}$ of the stationary variables $\Delta x_{t}$ and $v_{t}$ can be estimated by their sample counterparts. Definitions of the multivariate BN permanent component equivalent to (17) are used by KPSW and by Cochrane (1994) for the case of no structural breaks.

The permanent component obtained by the $\mathrm{BN}$ decomposition represents the long-run forecast of the series. More precisely, for an I(1) series, the BN permanent component is the limiting forecast of the random walk component of the series, once adjusted for deterministic growth. Nevertheless, it can be criticised as a measure of the structural trend in output. The permanent component does not contain any dynamics in the permanent and transitory shocks, as pointed out by Blanchard and Quah (1989) and Lippi and Reichlin (1994).

To address this problem, Gonzalo and Granger (1995) suggest a new permanent/transitory decomposition in which the permanent component incorporates some dynamics. Proietti (1997) noticed that the Gonzalo-Granger decomposition can be obtained as a relatively simple extension of the $\mathrm{BN}$ decomposition by substituting $\theta(1)$ for $\theta(L)$. In the context of the model in (17) this gives the permanent, or stochastic trend, component as:

$$
x_{t}^{P}=C(1) \theta(1) x_{t}-Q \gamma^{\prime}(t+1) \Xi_{t}+\delta_{o}
$$

which is the decomposition we use in section 7 of the paper.

\section{The evidence for structural breaks}

We now turn to analysis of the data. We use quarterly, seasonally adjusted data for 1955Q1 until 2001Q2 (for the UK) or 2002Q2 (for the US). The estimated models are based on data that start slightly later, to allow for initial conditions.

In section 2 above, we noted that stationarity is more likely to hold for current-price shares than the more problematic concept of "real shares". Hence we start by obtaining nominal series for GDP, consumption, investment, and government purchases, and quarterly data on population. We subtract government purchases from GDP to obtain a measure of nominal private sector output. 
We then divide this series, and those for consumption and investment, by the implicit price deflator for personal consumption expenditure, and by population. ${ }^{16}$ The resulting three variables are the measures of $Y, C$ and $I$ that we will use for testing the stationarity restrictions associated with a balanced growth path. We denote the natural logarithms of these variables by lower case letters $(y, c$, $i)$. We provide full details of the data sources in the data appendix.

The empirical analysis is relatively involved, and so we provide an overview here. Our first step is to investigate the order of integration of each series. ${ }^{17} \mathrm{We}$ then examine the evidence for stationarity of the great ratios without allowing for structural breaks, and show that the evidence for stationarity of both ratios is mixed at best, especially when using the Johansen procedure. We then investigate whether this result is due to structural breaks, using recently developed tests that identify possible break points and calculate confidence bands for the break dates. Applying these tests to our data, we find strong evidence of structural breaks. In the next section we will confirm that the evidence for stationary great ratios is stronger when structural breaks are taken into account. This result is not sensitive to the precise break dates.

We begin with unit root tests. For both countries, the null of a unit root cannot be rejected for any of the variables when using standard ADF tests. We also implement a more rigorous test that allows for structural breaks. For both countries, each variable was tested using the procedure of Banerjee et al. (1992) which allows for a break in the intercept (a mean shift) or a change in the slope of a deterministic trend (a trend shift).

For all the variables the null of a unit root is not rejected at conventional levels, even when allowing for structural breaks. For the US the test statistics for $c_{t}, i_{t}$, and $y_{t}$ allowing for mean shifts were respectively -4.78 (3), -4.37 (1) and -4.27 (1) using BIC to choose the lag length, reported in parenthesis. Critical values were obtained from Banerjee et al. (1992). The $5 \%$ critical value is -4.8 . When allowing for trend shifts, the test statistics were $-4.55(3),-4.13$ (1) and -4.12 (1). The critical value for a shift in trend is -4.48 . For the weakest of these results, $c_{t}$, at any other choice of lag length from 0 to 5 the null of a unit root could not be rejected. For the UK for $c_{t}, i_{t}$, and $y_{t}$ the test statistics allowing for mean shifts were $-3.54,-3.72$ and -3.66 and for trend shifts the test statistics were $-2.89,-2.60$ and -3.10 . The BIC selected zero lags for all cases but the null of a unit root could not be rejected at any other lag length from 1 to 5 either. Hence we treat the vector $x_{t}$ as $I(1)$ for both countries in the empirical work

\footnotetext{
${ }^{16}$ The use of per capita variables, and the decision to focus on private sector output, both follow the approach taken in KPSW.

${ }^{17}$ All computations were carried out in GAUSS (2001).
} 
that follows.

The KPSW arguments imply that log consumption and log investment should be cointegrated with log output, with coefficients of unity in the cointegrating vectors. The simplest way to test this is to impose the unit coefficients and use single-equation unit root tests on the log ratios. These tests usually fail to reject the null of a unit root (detailed results not reported). Since our theoretical prior is that the ratios are stationary, we have also used the Kwiatkowski et al. (1992) procedure, henceforth KPSS, which tests the null of stationarity against the alternative of a unit root. For the US, we could reject stationarity at the $5 \%$ level for the log consumption ratio with a test statistic of 0.838 but not for the $\log$ investment ratio with a test statistic of $0.141 .{ }^{18}$ The $5 \%$ critical value is 0.463 from KPSS (p. 166). For the UK the KPSS results are better: we could not reject stationarity for either of the great ratios with test statistics of 0.287 for the consumption ratio and 0.248 for the investment ratio.

We have also tested the stationarity hypothesis using the standard Johansen (1995) maximum likelihood procedure for estimating the cointegrating rank, again without assuming any structural breaks. We do not give all the results here but for each country we tested for cointegration in models with (i) restricted intercepts but no trends; (ii) unrestricted intercepts; (iii) unrestricted intercepts plus restricted trends.

For the US, using the trace statistic, there was evidence for only one cointegrating vector at the $5 \%$ level under specifications (i) and (iii). For specification (ii) there was some evidence for two cointegrating vectors. ${ }^{19}$ Under this specification the model has intercepts in the cointegrating equations only so that in (7) the intercept is $\theta_{o}=\beta \alpha_{o}^{\prime}$, where $\alpha_{o}$ is the vector of intercepts in the cointegrating equations. With this model, however, the unrestricted coefficient on log output in the log investment equation is much higher than unity, at 2.46 with a standard error of 0.28 . As this might suggest, a likelihood ratio test easily rejects the null of unit coefficients in the cointegrating vectors, with a test statistic of 13.34 and a p-value of 0.001 .

Overall, these findings conflict with the results of KPSW, who found much stronger evidence for two cointegrating vectors with unit coefficients for the US. Note that we are considering a more recent time period, 1955Q1-2002Q2 rather than the 1949Q1-1988Q4 period in KPSW. A time period closer to ours is

\footnotetext{
${ }^{18}$ We also considered the results when including a time trend. This did not alter our conclusions.

${ }^{19}$ With one lag first difference in the VECM, as selected by BIC, the trace test statistic was 30.5 for the null of one cointegrating vector against the alternative of two, with a $5 \%$ critical value of 19.96. The critical values are from Osterwald-Lenum (1992).
} 
considered in Bai, Lumsdaine and Stock (1998), whose sample ends in 1995Q4. They note (their footnote 11) that there is some evidence for highly persistent shifts in the share of output allocated to consumption, and possibly investment. This is consistent with our own findings from the KPSS tests, and the observed decline in the US saving ratio. These long-lived shifts in the great ratios may explain why the evidence for stationarity is relatively weak when applying the Johansen procedure to recent US data.

The results for the UK from the Johansen procedure also tend to reject stationarity of the great ratios. Under all three specifications, there was evidence for at most one cointegrating vector at the $5 \%$ level when using the trace statistic. This multivariate result for the UK is consistent with the work of Mills (2001), who found that the existence of two cointegrating vectors with unit coefficients could be rejected for the UK when using the Johansen procedure. ${ }^{20}$

It may seem surprising that the evidence for stationarity of the great ratios is not stronger. As argued previously, one reason for this result could be structural breaks in the great ratios, which make them appear non-stationary. We believe that a plausible process for the great ratios would be one in which the majority of shocks are transitory, combined with occasional mean shifts as the determinants of the ratios change.

With this in mind, we examine the case for stationarity when we adopt the generalized VECM formulation in (8) and test for cointegration allowing for structural breaks. The first step is to identify the break points in the system. There are a number of papers which suggest methods for finding break points in single equation cointegrating models, with well-known examples including Gregory and Hansen (1996) and Bai and Perron (1998). Recently Bai, Lumsdaine and Stock (1998), hereafter BLS, have provided a method for estimating confidence bands for break dates in multivariate systems. Importantly, they argue that tighter confidence bands can be obtained from a multivariate approach, and it is their tests that we adopt here.

The BLS method assumes a system of the form of (7) with given cointegrating vectors and estimates a confidence interval for a shift in the intercept in the VECM. Their model is the same as the specification in (8) when there is one mean break and the $\kappa_{j i}=0$ and $\gamma^{\prime}=0$. There are no trends in the cointegrating equation, and the model is similar to one with a break in a restricted intercept (that is, a model with an intercept, and shift in intercept, in the cointegrating equation only). The BLS test procedure is clearly a leading candidate for

\footnotetext{
${ }^{20} \mathrm{He}$ also presented the results of some alternative testing procedures, which provided stronger evidence for stationarity. We will show below that the Johansen procedure also indicates two cointegrating vectors, if structural breaks are incorporated.
} 
identifying structural breaks in a model such as ours, especially given that we have a strong prior on the cointegrating equations. Stationarity of the great ratios implies the following matrix of cointegrating vectors when the variables are ordered, $c_{t}, i_{t}$ and $y_{t}$ :

$$
\alpha^{\prime}=\left[\begin{array}{rrr}
-1 & 0 & 1 \\
0 & -1 & 1
\end{array}\right]
$$

Our strategy for locating break points was to apply the BLS multivariate test over the whole period with the $\alpha$ matrix constrained as above, and allowing the lag length in the VECM to be selected by the BIC. Having located one break point we then examined periods before and after the first break date, in order to locate any second structural break. We limit the number of breaks to two partly because, with the relatively small sample size available, allowing for more than two breaks would tend to blur the distinction between our null hypothesis (a stationary process with infrequent mean shifts) and a non-stationary process. This choice also simplifies the analysis, especially as we used the Johansen et al. (2000) test statistic for testing for the rank of the cointegrating space subject to structural shifts, and critical values for this test statistic are currently only available for a maximum of two breaks.

For the US for the whole sample the BLS procedure located 1982Q1 as a possible break point with a $90 \%$ confidence region of (1979Q3, 1984Q3). ${ }^{21}$ This break date closely coincides with the start of the long-term decline in the US saving ratio, typically dated around 1980 (Parker 1999). For the period 1955Q1 to 1978Q1, prior to the lower confidence limit for the first break, the BLS test indicated no significant break. For the period 1985Q1 to 2002Q1 there was a highly significant break at 1998Q2 with a 90\% confidence region of (1997Q4, 1998Q4). ${ }^{22}$

As a check, we have also applied the univariate procedures due to Bai and Perron (2003). Using the full sample their SupF statistic identified two breaks, at 1976Q4 and 1989Q2, for the log investment ratio and only one break, at 1985Q1, for the log consumption ratio. ${ }^{23}$ For the period up to 1978Q1 there were no significant breaks in the log consumption ratio but a break at 1964Q4 for the log investment ratio. When compared to the BLS procedure, the different

\footnotetext{
${ }^{21}$ The Sup-W and lExp-W test statistics were 11.77 (12.58) and $3.96(3.63)$ where the $10 \%$ critical values are in brackets. The lExp-W test statistic is significant at the $10 \%$ level, while the Sup-W statistic is approaching significance at the $10 \%$ level. Critical values were obtained by a simulation similar to those implemented in BLS.

${ }^{22}$ The Sup-W and lExp-W test statistics were 29.18 (18.39) and $11.56(6.10)$ which are both significant at the $1 \%$ level.

${ }^{23}$ The Bai and Perron procedures yield a battery of test statistics which are not reported here but can be obtained from the authors.
} 
outcomes indicate that dating structural breaks is an inexact science. We will base our later analysis on the BLS point estimates of the break dates, but will also examine robustness to alternative choices within the estimated confidence bands.

For the UK, the different procedures are in much closer agreement on possible break dates. For the whole sample the BLS procedure located a significant break point at 1990Q3 with 90\% confidence region of (1987Q4, 1993Q2). For the sample period up to and including 1986Q1 there was a break at 1963Q3 with $90 \%$ confidence region $(1962 \mathrm{Q} 4,1964 \mathrm{Q} 2) .{ }^{24}$ The period after $1993 \mathrm{Q} 2$ is too short to investigate structural breaks, so we take 1963Q3 and 1990Q3 as our candidate break dates. These results are strongly reinforced by applying the simpler univariate procedures of Bai and Perron (2003) to the full sample: their SupF statistic identified two breaks, at 1963Q3 and 1990Q3 for the log consumption ratio, and 1963Q4 and 1991Q2 for the log investment ratio. One possible explanation for the second break could be the extensive financial liberalization undertaken in the UK in the latter half of the 1980s.

Tables 1(a) and 1(b) summarise the point estimates and confidence bands for the break dates, as obtained by the BLS procedure, for the two economies.

\begin{tabular}{|c|c|c|}
\hline \multicolumn{3}{|c|}{ Table 1(a). Break Points for the US } \\
\hline $\begin{array}{c}\text { 90\% Lower bound } \\
\text { 1979Q3 }\end{array}$ & $\begin{array}{c}\text { Break Point } 1 \\
\text { 1982Q1 }\end{array}$ & $\begin{array}{c}\text { 90\% Upper bound } \\
\text { 1984Q3 }\end{array}$ \\
\hline $\begin{array}{c}\text { 90\% Lower bound } \\
\text { 1997Q4 }\end{array}$ & $\begin{array}{c}\text { Break Point } 2 \\
1998 Q 2\end{array}$ & $\begin{array}{c}\text { 90\% Upper bound } \\
\text { 1998Q4 }\end{array}$ \\
\hline \multicolumn{3}{|c|}{ Break Points for the UK } \\
\hline 90\% Lower bound & Break Point 1 & $90 \%$ Upper bound \\
\hline 1962Q4 & 1963Q3 & 1964Q2 \\
\hline $90 \%$ Lower bound & Break Point 2 & $90 \%$ Upper bound \\
\hline 1987Q4 & 1990Q3 & 1993Q2 \\
\hline
\end{tabular}

\section{Estimates of the cointegrating vectors}

The previous section has highlighted the possibility of mean shifts in the great ratios, reflected in breaks in the cointegrating equations. In this section, we will test for cointegration allowing for the structural breaks identified above and

\footnotetext{
${ }^{24}$ For the first break the Sup-W and $\mathrm{lExp}-\mathrm{W}$ test statistics were 15.65 (14.44) and 4.74 (4.43). For the second break we obtained Sup-W and lExp-W test statistics of 15.14 (14.44) and 3.55 (4.43). These are all significant at the $5 \%$ level except for 3.55 which is close to the $10 \%$ critical value.
} 
listed in Table 1. Our main result is that, allowing for these breaks, the Johansen procedure indicates the presence of two cointegrating vectors. The evidence for the unit coefficients implied by the balanced growth restriction is weaker, but the departures from unity are small in economic terms. When we impose unit coefficients and apply KPSS tests, again allowing for structural breaks, we fail to reject the null hypothesis that the great ratios are stationary. Finally, we are able to show that our results are quite robust to alternative choices of break dates.

We begin with the break points identified by the multivariate tests, and listed in Table 1 above. We test for cointegration in the presence of these two structural breaks using the recent results of Johansen et al. (2000). They derive the distribution of the trace test statistic for the rank of the cointegrating space in a model such as equation (8). They also calculate the weights for the estimated response surface to enable critical values to be easily calculated from a $\Gamma$ - distribution.

We assume a model with intercept shifts only so that the model in (8) becomes:

$$
\triangle x_{t}=\left(\theta_{o}+\beta \alpha_{o}^{\prime}\right) \Xi_{t}+\sum_{j=1}^{k} \theta_{j} \triangle x_{t-j}+\beta \alpha^{\prime} x_{t-1}+\sum_{i=1}^{k+1} \sum_{j=2}^{3} \kappa_{j i} D_{j t-i}+\zeta_{t} .
$$

where $\alpha_{o}^{\prime}$ is the vector of intercepts in the cointegrating equations. If $\theta_{o}=0$ then there are intercepts in the cointegrating equations only. If $\theta_{o} \neq 0$ and $\alpha_{o}^{\prime} \neq 0$ there is an unrestricted intercept in the VECM of the form:

$$
\left(\theta_{o}+\beta \alpha_{o}^{\prime}\right) \Xi_{t}
$$

so that $\theta_{o}$ and $\alpha_{o}^{\prime}$ cannot be identified.

Both these models are potentially consistent with the balanced growth restrictions, but the model with $\theta_{o}=0$ allows us to identify and estimate the coefficients on the breaks in the cointegrating equations. A likelihood ratio test of the model with $\theta_{o}=0$ against the model with $\theta_{o} \neq 0$ resulted in a chi square statistic, with 3 degrees of freedom, of 10.5 for the US and 10.4 for the UK. We cannot reject the null that $\theta_{o}=0$ at the $1 \%$ level but we can at the $5 \%$ level. With this in mind, we first present results with $\theta_{o}=0$, allowing us to obtain estimates of the shift parameters $\alpha_{o}^{\prime}$, and then present results for the case $\theta_{o} \neq 0$.

Using the model with restricted intercepts, we obtained the results in Table 2. Note that for the multivariate cases BIC and AIC were consistent in selecting 
one lag of first differences in the VECM (that is, two lags in levels).

\begin{tabular}{ccc|ccc}
\hline \hline \multicolumn{5}{c}{ Table 2. Tests of rank allowing for structural breaks } \\
\hline & US & & UK \\
Hypothesis & Test Statistic & p-value & Hypothesis & Test Statistic & p-value \\
$\mathrm{r}=0$ & 112.46 & 0.00 & $\mathrm{r}=0$ & 91.88 & 0.00 \\
$\mathrm{r} \leq 1$ & 40.63 & 0.01 & $\mathrm{r} \leq 1$ & 36.22 & 0.01 \\
$\mathrm{r} \leq 2$ & 14.33 & 0.07 & $\mathrm{r} \leq 2$ & 10.99 & 0.23 \\
\hline \hline
\end{tabular}

Allowing for the two break points selected previously, the likelihood rank test statistic rejects one cointegrating vector in favour of two and the null of two vectors is not rejected, for either the US or the UK. From now on, we assume that the rank of the cointegrating space is two.

Without any loss of generality we can interpret the first vector as a consumption equation and the second as an investment equation. With rank two, we can normalise two coefficients in the two equations. The first candidates are obviously the coefficients on $c_{t}$ and $i_{t}$, normalised at -1 . Since our focus is on the great ratios, it is natural to normalize the coefficient on log consumption in the investment equation (and log investment in the consumption equation) to zero. The cointegrating equations are therefore:

$$
\begin{array}{lllllll}
v_{1 t}= & -c_{t} & & +\alpha_{13} y_{t} & +\gamma_{11} & +\gamma_{12} & +\gamma_{13} \\
v_{2 t}= & & -i_{t} & +\alpha_{23} y_{t} & +\gamma_{21} & +\gamma_{22} & +\gamma_{23}
\end{array}
$$

where the $\gamma_{\mathrm{s}}$ represent the intercepts for the three periods defined by the two break points.

The hypothesis that the great ratios are stationary (allowing for two mean shifts) implies the unit coefficients restriction $\alpha_{13}=\alpha_{23}=1$. We have examined this null hypothesis for both countries using likelihood ratio tests. The switching algorithm technique of Doornik (1995) is used to estimate the restricted models and calculate asymptotic standard errors. The likelihood ratio test statistics were 7.4 (p-value 0.03) for the US and 6.52 (p-value 0.04) for the UK, with two degrees of freedom. This implies that the hypothesis of unit coefficients is rejected at the $5 \%$ level for both countries, although not at the $1 \%$ level. We show below that the departures from unity are relatively small in economic terms, for many possible break dates. ${ }^{25}$

We have also carried out KPSS single-equation tests of stationarity on the great ratios, imposing unit coefficients in $\alpha$ and allowing for the structural breaks

\footnotetext{
${ }^{25}$ There are certain break dates for which the coefficients are not significantly different from unity. The justification for these break dates would inevitably be slightly arbitrary, however. In the interests of overall rigour we have preferred to emphasize the point estimates of break dates indicated by the BLS procedure.
} 
indicated above. ${ }^{26}$ We cannot reject the null of stationarity at the $5 \%$ level for any of the cases considered. For the US the test statistics were 0.114 for the $\log$ consumption ratio and 0.180 for the $\log$ investment ratio $(5 \%$ critical value 0.181), while for the UK the same two test statistics were 0.071 and 0.052 (5\% critical value 0.173$)$. Hence the KPSS results for the US are much stronger when including structural breaks, as before we could reject stationarity of the log consumption ratio. The results are also stronger for the UK, since the test statistics are further away from rejecting the null than for the case without breaks.

Therefore, our main result is that, provided one allows for occasional mean shifts, there is evidence consistent with stationarity of the great ratios. Log consumption and log investment are each cointegrated with log output. Although the evidence for unit coefficients is weaker, the departures from unity are small in economic terms, as in Ahmed and Rogers (2000). The results imply that shocks to the ratios are predominantly transitory, consistent with the long-run predictions of the various models discussed in sections 2 and 4 above.

We now present detailed estimates of the consumption and investment equations for the two countries. Tables 3 and 4 show the results for the US and UK. Note that all the broken intercepts are significant, confirming the importance of structural breaks in the cointegrating equations. Tables 3 and 4 also report the Box-Ljung statistics, which are calculated from the residuals for the VECM equations for consumption and investment, with the number of terms equal to $\sqrt{T}$. In most cases, the results are consistent with the null hypothesis that the equation disturbances are white noise, although with a rejection at the $10 \%$ level for the US consumption equation.

\begin{tabular}{ccccccc}
\hline \hline \multicolumn{5}{c}{ Table 3(a). US consumption equation estimates } \\
\hline Variable & $c_{t}$ & $y_{t}$ & intercept $_{1}$ & intercept $_{2}$ & intercept $_{3}$ \\
Cointegrating Coefficients & -1 & 1 & -0.191 & -0.153 & -0.117 \\
Estimated Standard Errors & - & - & $(0.007)$ & $(0.008)$ & $(0.016)$ \\
Box-Ljung $(13)$ & $=19.79$, pval $=0.10$ & \\
\hline \hline
\end{tabular}

\footnotetext{
${ }^{26}$ To obtain the critical values where we have breaks in intercepts we simulated the model with 50000 replications on the null hypothesis (great ratios stationary, with breaks corresponding to those we have selected for each data set, and corresponding sample sizes).
} 


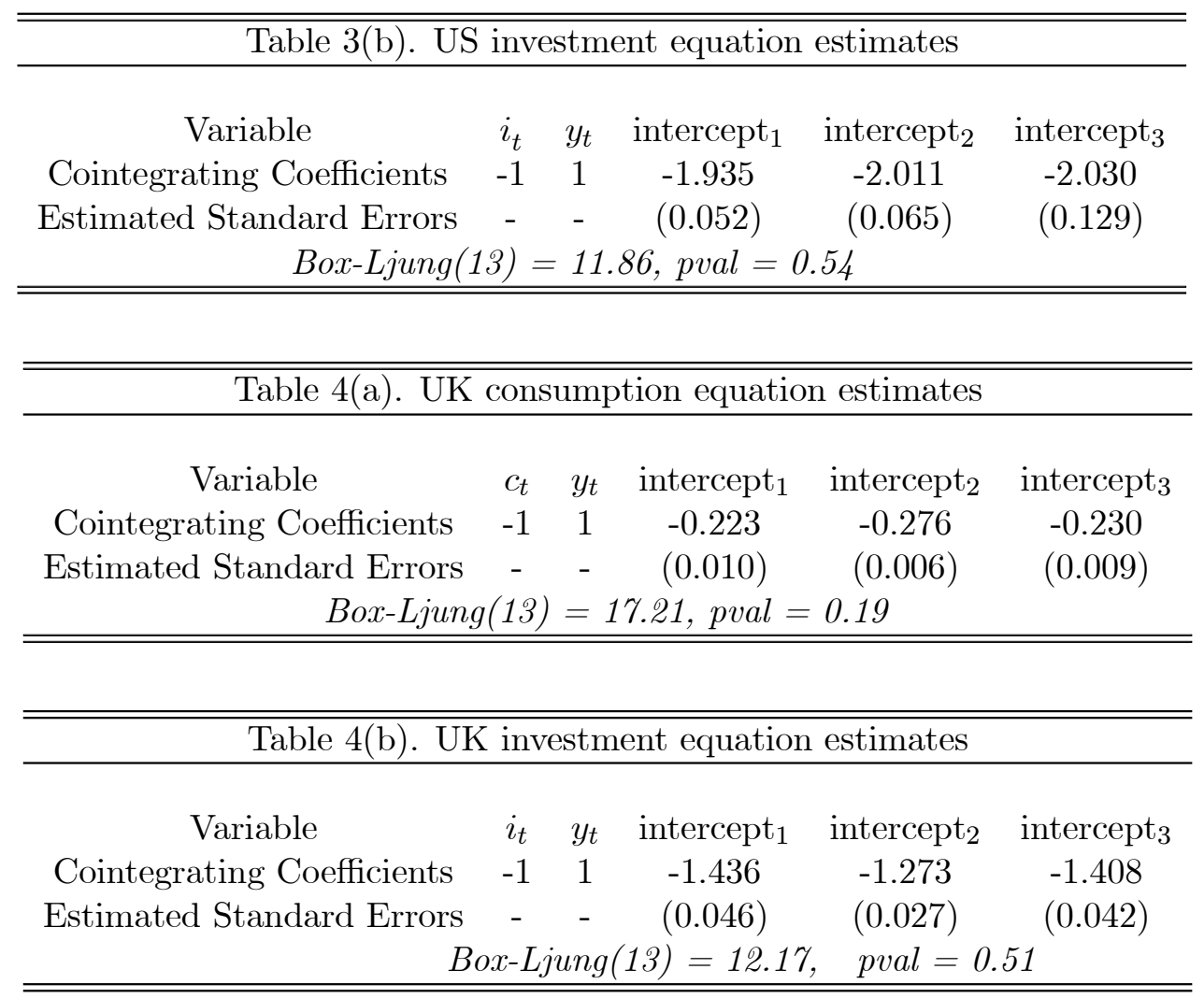

We now address the key issue of sensitivity to alternative break dates. Our main results are robust to most possible combinations of breaks within the confidence bands estimated by the BLS procedure. For the US the confidence bands were 1979Q3 to 1984Q3 and 1997Q4 to 1998Q4, which implies $21 \times 5=105$ possible combinations of two break dates (assuming just one within each band). For 104 of these 105 possible combinations, there was evidence for two cointegrating vectors at the $5 \%$ level. The exception was the combination of 1979Q4 and 1997Q4 where the two cointegrating vectors were significant only at the 7\% level. Across all 105 combinations, the coefficient on log output in the consumption equation ranges between 0.94 and 0.99 with a mean of 0.97 , and the coefficient on log output in the investment equation ranges between 1.14 and 1.41, with a mean of 1.27 . Hence, for most break dates, the departures from unit coefficients are relatively small in economic terms.

The results for the UK are also quite robust. The confidence bands for the UK were 1962Q4 to 1964Q2 and 1987Q4 to 1993Q2, implying $7 \times 23=$ 161 possible combinations. Of these, 79 combinations yielded two cointegrating vectors at the $5 \%$ level, 31 between the $5 \%$ and $10 \%$ levels, 33 between $10 \%$ and $20 \%$ and only 18 greater than $20 \%$, with the weakest result (1964Q2, 1992Q4) 
found at one extreme of the confidence bands. Across all 161 combinations, the coefficient on log output in the consumption equation ranges between 1.01 and 1.11 with a mean of 1.06 , while the coefficient on log output in the investment equation ranges between 0.84 and 1.48 with a mean of 1.19 .

We turn now to the case with $\theta_{o} \neq 0$. This corresponds to an unrestricted matrix of breaking intercepts in the VECM, which can be interpreted as breaking drift terms in the processes generating the variables $c_{t}, i_{t}$, and $y_{t}$ and breaking intercepts in the two cointegrating equations (with the same break dates for the drift terms and the intercepts). In many respects, the results for the unrestricted model are more robust. Table 5 gives the results of tests for the rank of the cointegrating space. The critical values and p-values are obtained from Theorem 3.3 in Johansen et al (2000).

\begin{tabular}{ccc|ccc}
\hline \hline \multicolumn{5}{c}{ Table 5. Tests of Rank - Unrestricted Model } \\
\hline Hypothesis & Test Statistic & p-value & Hypothesis & Test Statistic & p-value \\
r $=0$ & 45.89 & 0.00 & $\mathrm{r}=0$ & 45.51 & 0.00 \\
$\mathrm{r} \leq 1$ & 19.87 & 0.00 & $\mathrm{r} \leq 1$ & 21.07 & 0.00 \\
$\mathrm{r} \leq 2$ & 2.18 & 0.13 & $\mathrm{r} \leq 2$ & 0.43 & 0.51 \\
\hline \hline
\end{tabular}

Allowing for the two break dates selected previously, the likelihood rank test statistic rejects one cointegrating vector in favour of two and the null of two vectors is not rejected, for either the US or the UK. As for the restricted model, we can conclude that there are two cointegrating equations. As before, we normalise these to be consumption and investment equations. A likelihood ratio test of the null of unit coefficients on output in both equations resulted in a test statistic of $6.08(\mathrm{p}$-val $=0.05)$ for the US and $7.83(\mathrm{p}$-val $=0.02)$ for the UK. Although unit coefficients are rejected at the $5 \%$ level, the departures from unity are usually small in economic terms, as we document below. Using the Box-Ljung statistic the hypothesis of white noise errors in the VECM is not rejected at conventional levels.

The sensitivity of the unrestricted model to the choice of break dates is similar to that found for the restricted case. For the US, we again consider the confidence intervals 1979Q3 to 1984Q3 and 1997Q4 to 1998Q4. For all the $21 \times$ $5=105$ possible combinations, there was evidence for two cointegrating vectors at the $5 \%$ level. Across all combinations, the mean coefficient on log output in the consumption equation was 0.98 and the coefficient ranged between 0.96 and 0.99. Less favourably, the mean coefficient on log output in the investment equation was 1.20 and the coefficient ranged between 1.12 and 1.26.

For the UK we again consider the two confidence intervals 1962Q4 to 1964Q2 
and 1987Q4 to 1993Q2. For the $7 \times 23=161$ possible combinations, 125 had two cointegrating vectors at the $5 \%$ level, 12 between the $5 \%$ and $10 \%$ levels, and only 24 failed to have two cointegrating vectors at the $10 \%$ level. Again, the weakest results are at the very border of the confidence bands. In the consumption equation, the mean coefficient on log output was 1.06, with the coefficient ranging between 1.02 and 1.13 across all 161 break combinations in the confidence bands. In the investment equation, the results were again less strong, with much greater sensitivity of the output coefficient to precise break dates: the mean coefficient on log output was 1.10, the coefficient ranging between 0.59 and 1.38 .

We end our discussion of these results by noting an important dimension in which they are less robust. A case could be made for the inclusion of time trends in the cointegrating equations, perhaps as a way to capture slow evolution of the determinants of the ratios as a sample property. Such trends are often significant when included in the cointegrating equations. Their role could only be temporary, however, given that the ratios are bounded above and below, and including them tends to weaken the results. In the model with time trends, it is still possible to find evidence for unit cointegrating vectors, but this result is highly sensitive to the specific break dates. Moreover, the break dates that give the strongest results always lie outside the confidence bands identified by the formal tests for structural breaks. We therefore report only the results which exclude time trends from the cointegrating equations. We should note that for one of our main tasks, extracting the permanent component in output as in the next section, our findings are quite similar even if trends are included in the cointegrating equations.

\section{The permanent component in output}

Using the methods described in section 4, we can now extract an estimate of the permanent component from the VECM. For this purpose, we use the more general model with unrestricted broken intercepts. This is not significantly different from one with restricted broken intercepts, and gives smoother estimates of the stochastic trend. Having extracted the permanent component in output in this way, we will then compare it with the permanent component implied by a standard univariate decomposition.

First, we note that our estimated model gives rise to sharp discontinuities in the permanent component, corresponding to the dates of structural breaks. This follows from the BN definition of permanent components as limiting forecasts. 
If the model undergoes a structural change, this will modify estimates of the rate of drift and/or expected future changes in output, so that the limiting forecast of the output series must change at the date of the structural break. In the multivariate context, another way to make this point is to observe that the multivariate BN permanent components, as the long-run forecasts, must always be cointegrated if the great ratios are stationary. It follows that, if there is a discrete mean shift in the equilibrium great ratios, the long-run forecasts may also have to undergo a discrete jump.

To some extent, these discontinuities can be seen as artifacts generated by the assumption of sharp, discrete structural breaks, rather than more gradual changes in parameters that are harder to deal with statistically. ${ }^{27}$ This means that the breaks in the permanent component should not be interpreted too literally, and it is the long-term patterns that are of most interest. Put differently, there is a sense in which a BN decomposition, as a limiting forecast, says more about the future movements in output that are to be expected from a given point onwards, rather than estimating productive potential at each instant of time. It follows that the BN permanent components may not evolve smoothly through time, even if productive potential is generally expected to do so.

Extending the analysis of section 4 above, the presence of discontinuities can be seen more formally as follows. The permanent component for the model with no trends in the cointegrating equations, $\gamma^{\prime}=0$, but shifts in an unrestricted intercept in the VECM, is given by:

$$
x_{t}^{P}=C(1) \theta(1) x_{t}+\delta_{o}
$$

where $\delta_{o}=-C(1) \theta^{*}(1) \mu_{\triangle x}+Q \mu_{v}$. Integrating the model in (10) we obtain the solution for $x_{t}$ as:

$$
x_{t}=x_{o}+C(1) \sum_{i=1}^{t} \zeta_{i}+\mu_{\triangle x} t+S_{t}
$$

where $x_{o}$ is an intial value for the process and where $S_{t}=C^{*}(L) \zeta_{t}$ - see, for comparison, Johansen (1995, ch. 5). Substituting for $x_{t}$ in the permanent component yields:

$$
x_{t}^{P}=C(1) \theta(1) x_{o}+C(1) \sum_{i=1}^{t} \zeta_{i}+C(1) \theta(1) \mu_{\triangle x} t+C(1) \theta(1) S_{t}+C(1) \theta(1) \delta_{o}
$$

\footnotetext{
${ }^{27}$ See the introduction to Hansen (2001), who writes "While it may seem unlikely that a structural break could be immediate, and might seem more reasonable to allow for a structural change to take a period of time to take effect, we most often focus on the simple case of an immediate structural break for simplicity and parsimony".
} 
since $C(1) \theta(1) C(1)=C(1)$. It is easily deduced that $\mu_{\triangle x}=C(1) \mathcal{K}_{o} H_{t}$ where:

$$
H_{t}=\left[\begin{array}{c}
\Xi_{t} \\
D_{1}
\end{array}\right]
$$

and $\mathcal{K}_{o}=\left(\theta_{o}, \varkappa\right)$ as in section 3 so it follows that the slope of the linear time trend in the permanent component will depend upon the sub-period of the sample through the break dummies in $\Xi_{t}$. Further, it is easily deduced that:

$$
\begin{aligned}
\delta_{o} & =-C(1) \theta^{*}(1) \mu_{\triangle x}+Q \mu_{v} \\
& =-\left[C(1) \theta^{*}(1) C(1)+Q\left(\alpha^{\prime} \theta(1)^{-1} \beta\right)^{-1} \theta(1)^{-1}\right] \mathcal{K}_{o} H_{t}
\end{aligned}
$$

so that intercepts for each of the sub-periods will also differ through $\mathcal{K}_{o} H_{t}$.

We now present our estimates of the permanent component, before comparing them with a simple univariate decomposition. The estimates are shown in Figure 6, which plots the log of the output series (the dotted line) and the permanent component (the solid line) for both the US and the UK. The permanent components are those based on the multivariate Gonzalo-Granger-Proietti decomposition for each country.

Given the empirical method we have adopted, based on relatively weak longrun restrictions, our interest is more in the long-term pattern of the permanent component than in the short-run disparity between output and the permanent component. In other words, this procedure may be poorly suited to measuring potential output, not least because it makes no use of unemployment or inflation data, and also because of the restrictions embodied in the GonzaloGranger-Proietti decomposition. The great ratios approach may nevertheless be quite informative about long-term shifts in the behaviour of the permanent component, given that this component is being identified using the joint behaviour of consumption, investment and output.

We look first at the case of the US (the upper panel) beginning in the mid1970s. Here we see that the permanent component of output grew very slowly in the 1970s, consistent with the much-discussed productivity slowdown that revealed itself over the course of the decade. The growth of the permanent component is more rapid in the 1980s. The results for the 1990s are of especial interest, since they appear to reflect the New Economy boom of this period. Our analysis clearly indicates that the rate of output growth observed in the 1990s was higher than the rate of growth of the permanent component, reflecting favourable transitory shocks. For the short period after the structural break of the late 1990s, however, this is no longer true. The permanent component is seen to have grown more rapidly than output. Hence, the joint behaviour of 
consumption, investment and output predicted that trend growth would continue to be strong. ${ }^{28}$

The results for the UK (the lower panel) are shown for the 1960s onwards, and are less striking than for the US. The permanent component varies in a similar way to observed output, and indicates that the multivariate approach is relatively uninformative in the case of the UK. To investigate this further, we now compare the VECM decomposition with a simple univariate trend, for both countries.

For the univariate trend we adopt the Beveridge-Nelson decomposition. This is a natural counterpart to our multivariate decomposition, and interest in the BN decomposition has recently been increased by the work of Morley, Nelson and Zivot (2003). For a specific family of unobserved component models, they estimate the correlation between trend and cycle disturbances to be close to minus one, the correlation that is present by construction in the BN estimates of trend and cyclical components. The finding can be given an economic interpretation if productivity shocks are an important source of fluctuations. A positive shock to productivity will increase trend output, but this implies output will be below trend for a transitory period. Hence innovations to the trend are negatively correlated with cyclical innovations, as in the BN decomposition. ${ }^{29}$

Figure 7 compares our multivariate trend, with structural breaks, to a univariate trend based on the BN decomposition for output. As is often found, the permanent component identified by the univariate $\mathrm{BN}$ decomposition is almost indistinguishable from actual output, implying that most of the variation in output is driven by permanent shocks (innovations to the trend). In figure 7 the univariate trend is based on 8 lags of first differences and still appears to account for most of the fluctuations in actual output shown in figure 6 . The use of BIC suggested only one lag in first differences for both countries.

By comparing our multivariate estimates with a univariate decomposition, Figure 7 clearly reveals the potential usefulness of the multivariate approach. For the US (the upper panel) the pattern observed earlier is much less clear in the univariate decomposition (the dotted line) than in the multivariate decomposition (the solid line). The univariate decomposition does not indicate the slow trend growth of the 1970s, or the above-trend growth of the mid-1990s,

\footnotetext{
${ }^{28}$ This result does require some qualification, because the second break point for the USA is close to the end of the sample. This means that any conclusions about recent movements in trend output can only be tentative.

${ }^{29}$ Note, however, that a range of models are consistent with correlated components. See Proietti (2006) for further discussion, and Morley (forthcoming) for a paper which studies the relationship between consumption and income under more general assumptions about the correlations between permanent and transitory components of the two series.
} 
as clearly as the multivariate approach. Overall, it is clear that the multivariate approach can offer some useful insights into the evolution of the permanent component, and could provide a useful complement to univariate trend analysis.

\section{Conclusions}

This paper has revisited the stationarity of the great ratios of consumption to output, and investment to output. We have taken as our starting point the work of KPSW, one of the most widely cited papers in macroeconometrics. The central focus of KPSW was on the relative importance of different forms of shocks in explaining short-run fluctuations. Their examination of the joint behaviour of consumption, investment and output also offered a new approach to measuring trend output, based on extracting the common permanent component from a multivariate system.

We extend the work of KPSW partly by focusing on the great ratios expressed in current-price terms. As we have discussed, the current-price ratios will be stationary under more general conditions than the constant-price ratios. Our paper also extends their analysis in a number of other ways. One motivation for these extensions is that researchers who have followed KPSW have often rejected the hypothesis that the great ratios are stationary. Sometimes, researchers have used this finding as evidence against models of exogenous growth. The problem with this argument is that other standard models would also yield a balanced growth path, including a wide range of endogenous growth models.

One resolution to this puzzle is to acknowledge that empirical testing of theoretical models inevitably requires some strong auxiliary assumptions, notably parameter constancy, and so it is a joint hypothesis that is being tested. Our analysis takes the possibility of parameter variation into account. We think that a plausible statistical model for the great ratios is one in which the majority of shocks are transitory, but occasional mean shifts are possible, reflecting changes in the underlying structural parameters such as the trend growth rate and the discount factor. Consistent with this hypothesis, if we allow for structural breaks in the equilibrium great ratios, the evidence for two cointegrating vectors in both the US and the UK is much stronger than before.

Our second main contribution builds on the first. If the great ratios are stationary, we can use the associated long-run restrictions to measure trend output using information from consumption and investment, as well as past output. This procedure is attractive because it uses information from several series to derive the expected path of trend output, without any need to articulate 
a full structural model. In a development new to this paper, we show how this approach can be implemented even when there are structural breaks in the underlying stationary processes.

We obtain some interesting findings, especially for the US. Perhaps most revealing are the results for the New Economy period. The joint behaviour of consumption, investment and output indicates that strong growth in the 1990s was partly due to transitory favourable shocks, as sometimes suggested at the time. By 2002, however, the extracted permanent component is seen to grow more strongly than observed output. Hence, a researcher using this method might have concluded that recent improvements in performance would be sustainable. This prediction has arguably been confirmed out-of-sample, by continuing strong productivity growth in the US in the early 2000s.

\section{Data}

For the US, the data series were downloaded from the Bureau of Economic Analysis website. The data are seasonally adjusted (SA) and expressed as annual rates, with the exception of population, which is measured mid-period. The output figures are for GDP, while government expenditure corresponds to government consumption and gross investment. The price index we use is the implicit price deflator for personal consumption expenditure.

For the UK, the data series were constructed from the following series in the Economic Trends Annual Supplement (2001): Households Final Consumption Expenditure, current prices, code ABJQ; Households Final Consumption Expenditure, 1995 prices, code ABJR; GDP at market prices, 1995 prices, code ABMI; GDP at market prices per capita, 1995 prices, code IHXW; Gross Domestic Product at market prices, current prices, code YBHA; Government Final Consumption Expenditure, current prices, code NMRP; Gross Fixed Capital Formation, current prices, code NPQS. Note that for the UK, for data availability reasons, our measure of government expenditure corresponds to government consumption, and government investment is included in our measure of investment.

The price index, $p$, is obtained from the ratio ABJQ/ABJR. A population series, $N$, is obtained from ABMI/IHXW. Real per capita consumption is then defined as $C_{t}=\mathrm{ABJQ} /(p * N)$, real per capita investment as $I_{t}=\mathrm{NPQS} /(p * N)$ and real per capita private sector output, $Y_{t}=(\mathrm{YBHA}-\mathrm{NMRP}) /(p * N)$. Note that $C_{t}$ and $I_{t}$ do not sum to $Y_{t}$ because of the current account, and small discrepancies due to consumption of non-profit institutions, inventory adjustments, 
and measurement errors in the national accounts statistics.

\section{References}

[1] Abel, Andrew B. (2003). The effects of a baby boom on stock prices and capital accumulation in the presence of social security. Econometrica, 71(2), 551-578.

[2] Ahmed, Shaghil and John H. Rogers (2000). Inflation and the great ratios: long term evidence from the US. Journal of Monetary Economics, 45, 3-35.

[3] Attfield, Cliff L. F. (2003). Structural breaks and permanent trends. Department of Economics, University of Bristol discussion paper no. 03/545.

[4] Beveridge, Stephen and Charles R. Nelson (1981). A new approach to decomposition of economic time series into permanent and transitory components with particular attention to measurement of the 'business cycle'. Journal of Monetary Economics, 7, 151-74.

[5] Bai, Jushan and Pierre Perron (1998). Estimating and testing linear models with multiple structural changes. Econometrica, 66(1), 47-78.

[6] Bai, Jushan and Pierre Perron (2003). Computation and analysis of multiple structural change models. Journal of Applied Econometrics, 18(1), 1-22.

[7] Bai, Jushan, Robin L. Lumsdaine and James H. Stock (1998). Testing for and dating common breaks in multivariate time series. Review of Economic Studies, 65, 395-432.

[8] Banerjee, Anindya, Robin L. Lumsdaine and James H. Stock (1992). Recursive and sequential tests of the unit-root and trend-break hypotheses: theory and international Evidence. Journal of Business and Economic Statistics, 10, 271-287.

[9] Benati, Luca (2006). Drifts and breaks in labour productivity. CEPR discussion paper no. 5801.

[10] Ben-David, Dan and David H. Papell (1998). Slowdowns and meltdowns: postwar growth evidence from 74 countries. Review of Economics and Statistics, 80(4), 561-571.

[11] Ben-David, Dan and David H. Papell (2000). Some evidence on the continuity of the growth process among the G-7 countries. Economic Inquiry, 38(2), 320-330.

[12] Bentolila, Samuel and Gilles Saint-Paul (2003). Explaining movements in the labour share. Contributions to Macroeconomics, 3(1), Article 9. 
[13] Blanchard, Olivier J. (1997). The medium run. Brookings Papers on Economic Activity, 89-141.

[14] Blanchard, Oliver Jean and Danny Quah, (1989). The dynamic effects of aggregate demand and supply disturbances. American Economic Review, $79,655-73$.

[15] Clemente, Jesus, Antonio Montanes and Montserrat Ponz (1999). Are the consumption/output and investment/output ratios stationary? An international analysis. Applied Economics Letters, 6, 687-691.

[16] Cochrane, John H. (1994). Permanent and transitory components of GNP and stock prices. Quarterly Journal of Economics, 241-65.

[17] Cogley, Timothy (2005). How fast can the New Economy grow? A Bayesian analysis of the evolution of trend growth. Journal of Macroeconomics, 27(2), 179-207.

[18] Cook, S. (2005). The stationarity of consumption-income ratios: evidence from minimum LM unit root testing. Economics Letters, 89, 55-60.

[19] Cooley, Thomas F. and Mark Dwyer (1998). Business cycle analysis without much theory: a look at structural VARs. Journal of Econometrics, 83(1-2), $57-88$.

[20] D'Adda, Carlo and Antonello E. Scorcu (2003). On the time stability of the output-capital ratio. Economic Modelling, 20, 1175-1189.

[21] Daniel, Betty C. (1997). International interdependence of national growth rates: a structural trends analysis. Journal of Monetary Economics, 40, 73-96.

[22] DeLoach, Stephen B. and Robert H. Rasche (1998). Stochastic trends and economic fluctuations in a large open economy. Journal of International Money and Finance, 17, 565-596.

[23] Diebold, F. X., and A. Inoue (2001). Long memory and regime switching. Journal of Econometrics, 105, 131-159.

[24] Doornik, Jurgen A. (1995). Testing general restrictions on the cointegrating space. Manuscript, Nuffield College, Oxford.

[25] Eaton, Jonathan (1981). Fiscal policy, inflation and the accumulation of risky capital. Review of Economic Studies, 48(3), 435-445.

[26] Economic Trends Annual Supplement (2001), HMSO, London.

[27] Engle, Robert F. and Clive W.J. Granger (1987). Co-integration and error correction: representation, estimation and testing. Econometrica, 55, 251276 . 
[28] Erceg, C. J., L. Guerrieri and C. Gust (2005). Can long-run restrictions identify technology shocks? Journal of the European Economic Association, $3(6), 1237-1278$.

[29] Evans, Paul (2000). US stylized facts and their implications for growth theory. Manuscript, Ohio State University.

[30] Fama, Eugene F. (1992). Transitory variation in investment and output. Journal of Monetary Economics, 467-480.

[31] Fisher, Lance A., Hyeon-seung Huh and Ellis W. Tallman (2003). Permanent income and transitory variation in investment and output. Journal of Macroeconomics, 25, 149-168.

[32] Galí, Jordi (1999). Technology, employment, and the business cycle: do technology shocks explain aggregate fluctuations? American Economic Review, 89(1), 249-271.

[33] Garratt, Anthony, Kevin Lee, M. Hashem Pesaran and Yongcheol Shin (2003). A long run structural macroeconometric model of the UK. Economic Journal, 113(487), 412-455.

[34] Garratt, Anthony, Donald Robertson and Stephen Wright (2006). Permanent vs transitory components and economic fundamentals. Journal of Applied Econometrics, 21, 521-542.

[35] GAUSS (2001). Mathematical and Statistical System, Aptech Systems Incorporated, 23804 SE Kent-Kangley Road, Maple Valley, WA 98038 US.

[36] Gonzalo, Jesus and Clive W. J. Granger (1995). Estimation of common long-memory components in cointegrated systems. Journal of Business and Economic Statistics, 13, 27-35.

[37] Gordon, Robert J. (2000). Does the "New Economy" measure up to the great inventions of the past? Journal of Economic Perspectives, 14(4), 4974 .

[38] Greenwood, Jeremy, Zvi Hercowitz and Per Krusell (1997). Long-run implications of investment-specific technological change. American Economic Review, 87(3), 342-362.

[39] Gregory, Allan W. and Bruce E. Hansen (1996). Residual-based tests for cointegration in models with regime shifts. Journal of Econometrics, 70, pp.99-126.

[40] Hansen, Bruce E. (2001). The new econometrics of structural change: dating breaks in US labor productivity. Journal of Economic Perspectives, $15(4), 117-128$. 
[41] Johansen, Søren (1995). Likelihood-based inference in cointegrated vector auto-regressive models. Oxford University Press, Oxford.

[42] Johansen, Søren, Rocco Mosconi and Bent Nielsen (2000). Cointegration analysis in the presence of structural breaks in the deterministic trend. Econometrics Journal, 3, 216-249.

[43] Kim, Chang-Jin, Jeremy M. Piger and Richard Startz (forthcoming). The dynamic relationship between permanent and transitory components of US business cycles. Journal of Money, Credit, and Banking, forthcoming.

[44] King, Robert G., Charles I. Plosser and Sergio Rebelo (1988). Production, growth and business cycles, I: The basic neoclassical model. Journal of Monetary Economics, 21, no. 2/3, 195-232.

[45] King, Robert G., Charles I. Plosser and Sergio Rebelo (2002). Production, growth and business cycles: technical appendix. Computational Economics, $20(1-2), 87-116$.

[46] King, Robert G., Charles I. Plosser, James H. Stock and Mark W. Watson (1991). Stochastic trends and economic fluctuations. American Economic Review, 81, pp.819-840.

[47] Kwiatkowski, Denis, Peter C.B. Phillips, Peter Schmidt and Yongcheol Shin (1992). Testing the null hypothesis of stationarity against the alternative of a unit root. Journal of Econometrics, 54(1-3), pp.159-78.

[48] Lau, Sau-Him Paul and Chor-Yiu Sin (1997). Observational equivalence and a stochastic cointegration test of the neoclassical and Romer's increasing returns models. Economic Modelling, 14, 39-60.

[49] Lippi, Marco and Lucrezia Reichlin (1994). Diffusion of technical change and the decomposition of output into trend and cycle. Review of Economic Studies, 61, pp.19-30.

[50] Mellander, E., A. Vredin and A. Warne (1992). Stochastic trends and economic fluctuations in a small open economy. Journal of Applied Econometrics, 7(4), 369-394.

[51] Mills, Terence C. (2001). Great ratios and common cycles: do they exist for the UK? Bulletin of Economic Research, 53(1), 35-51.

[52] Morley, J. C. (forthcoming). The slow adjustment of aggregate consumption to permanent income. Journal of Money, Credit, and Banking, forthcoming.

[53] Morley, J. C., Nelson, C. R. and Zivot, E. (2003). Why are the BeveridgeNelson and unobserved-component decompositions of GDP so different? Review of Economics and Statistics, 85(2), 235-243. 
[54] Osterwald-Lenum, Michael (1992). A note with quantiles of the asymptotic distribution of the maximum likelihood cointegration rank test statistics. Oxford Bulletin of Economics and Statistics, 54, pp.461-472.

[55] Paap, R. and van Dijk, R. (2003). Bayes estimates of Markov trends in possibly cointegrated series: an application to U.S. consumption and income. Journal of Business and Economic Statistics, 21(4), 547-563.

[56] Palumbo, M., Rudd, J. and Whelan, K. (2006). On the relationships between real consumption, income and wealth. Journal of Business and Economic Statistics, 24(1), 1-11.

[57] Parente, S. L. and Prescott, E. C. (2000). Barriers to riches. MIT Press, Cambridge, MA.

[58] Parker, Jonathan (1999). Spendthrift in America? On two decades of decline in the US saving rate. NBER Macroeconomics Annual, 317-370.

[59] Proietti, Tommaso (1997). Short-run dynamics in cointegrated systems. Oxford Bulletin of Economics and Statistics, 59, pp.405-422.

[60] Proietti, Tomasso (2006). Trend-cycle decompositions with correlated components. Econometric Reviews, 25(1), 61-84.

[61] Romer, Paul M. (1986). Increasing returns and long-run growth. Journal of Political Economy, 94(5), 1002-37.

[62] Serletis, Apostolos (1994). Testing the long-run implications of the neoclassical growth model for Canada. Journal of Macroeconomics, 16(2), 329-346.

[63] Serletis, Apostolos (1996). Government activities and tests of the long-run implications of the neoclassical growth model for Canada. Canadian Journal of Economics, 29(3), 635-642.

[64] Serletis, Apostolos and Krichel, Thomas (1995). International evidence on the long-run implications of the neoclassical growth model. Applied Economics, 27, 205-210.

[65] Shapiro, M. and Watson, M. W. (1988). Sources of business cycle fluctuations. NBER Macroeconomics Annual, 111-148.

[66] Soderlind, Paul and Anders Vredin (1996). Applied cointegration analysis in the mirror of macroeconomic theory. Journal of Applied Econometrics, 11(4), 363-381.

[67] Tevlin, Stacey and Karl Whelan (2003). Explaining the investment boom of the 1990s. Journal of Money, Credit, and Banking, 35(1), 1-22.

[68] Whelan, Karl (2002). A guide to US chain aggregated NIPA data. Review of Income and Wealth, 48(2), 217-233. 
[69] Whelan, Karl (2003). A Two-Sector Approach to Modeling U.S. NIPA Data. Journal of Money, Credit, and Banking, 35(4), 627-656. 


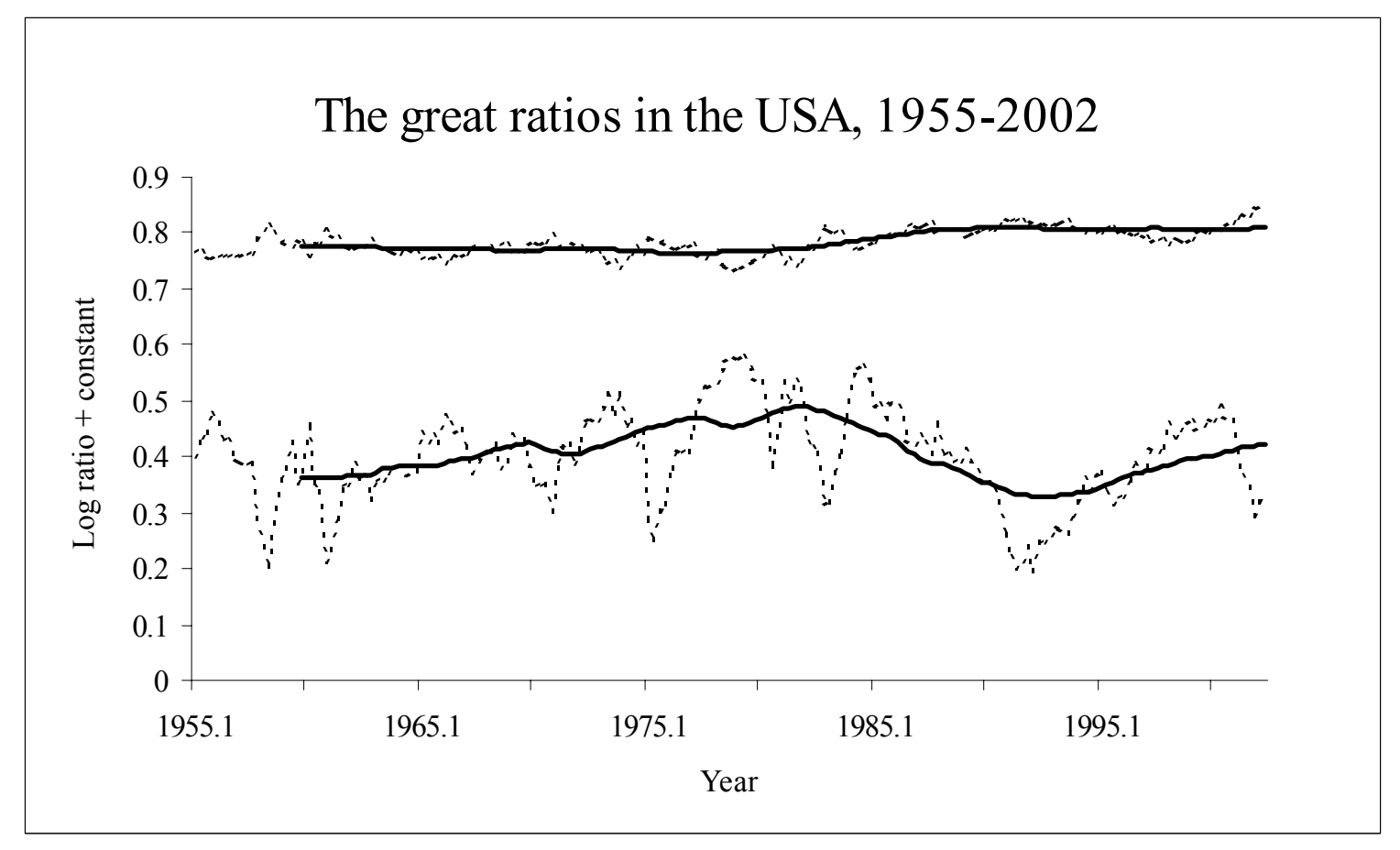

Figure 1: The plot shows the great ratios, in logarithms, for the USA, together with a centred 10-year moving average. The upper line is the log consumption ratio, and the lower line the log investment ratio. Constants have been added to the ratios to facilitate graphing.



Figure 2: The plot shows the great ratios, in logarithms, for the UK, together with a centred 10-year moving average. The upper line is the log consumption ratio, and the lower line the log investment ratio. Constants have been added to the ratios to facilitate graphing. 


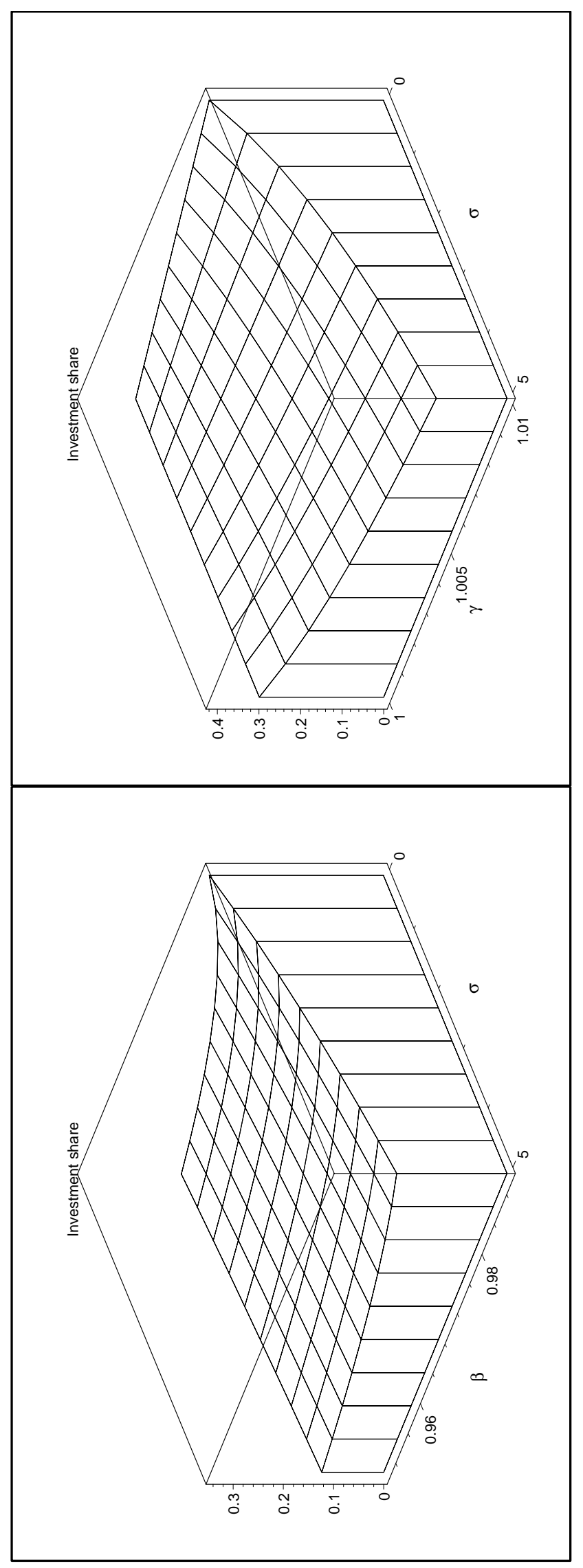

Figures 3 and 4 


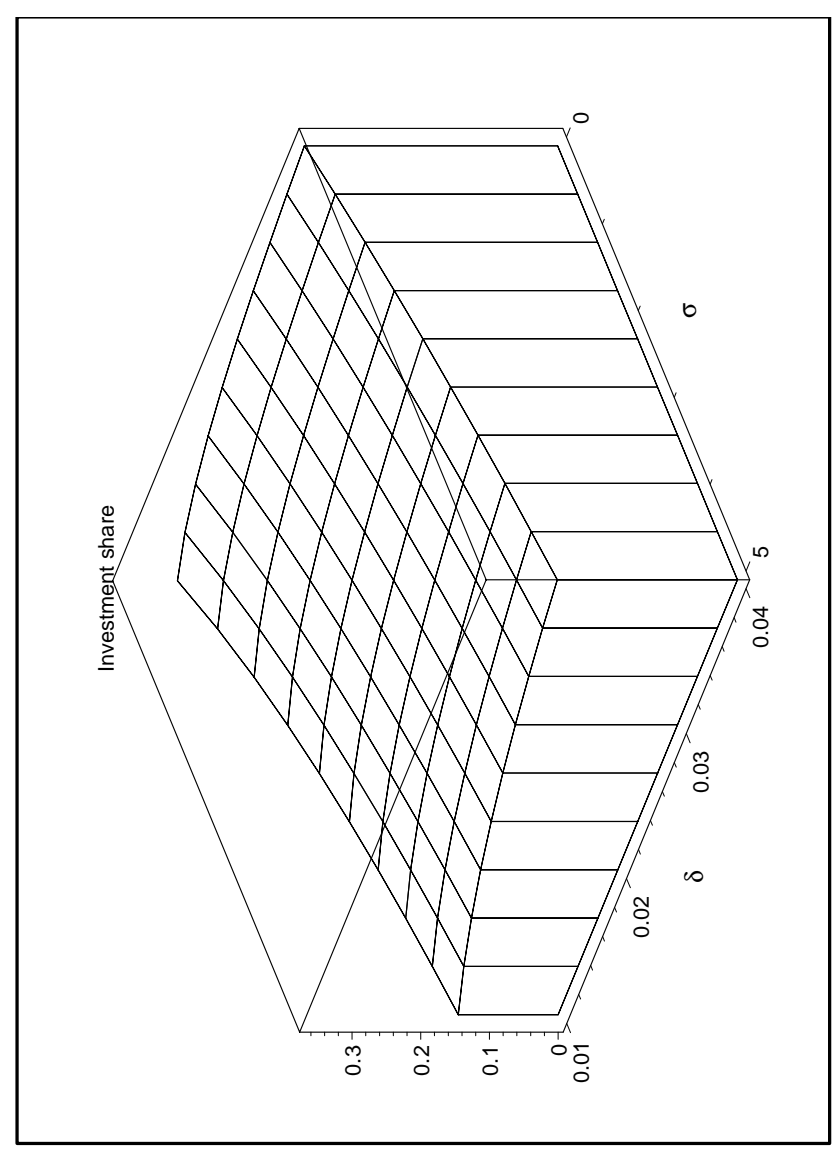

Figure 5 

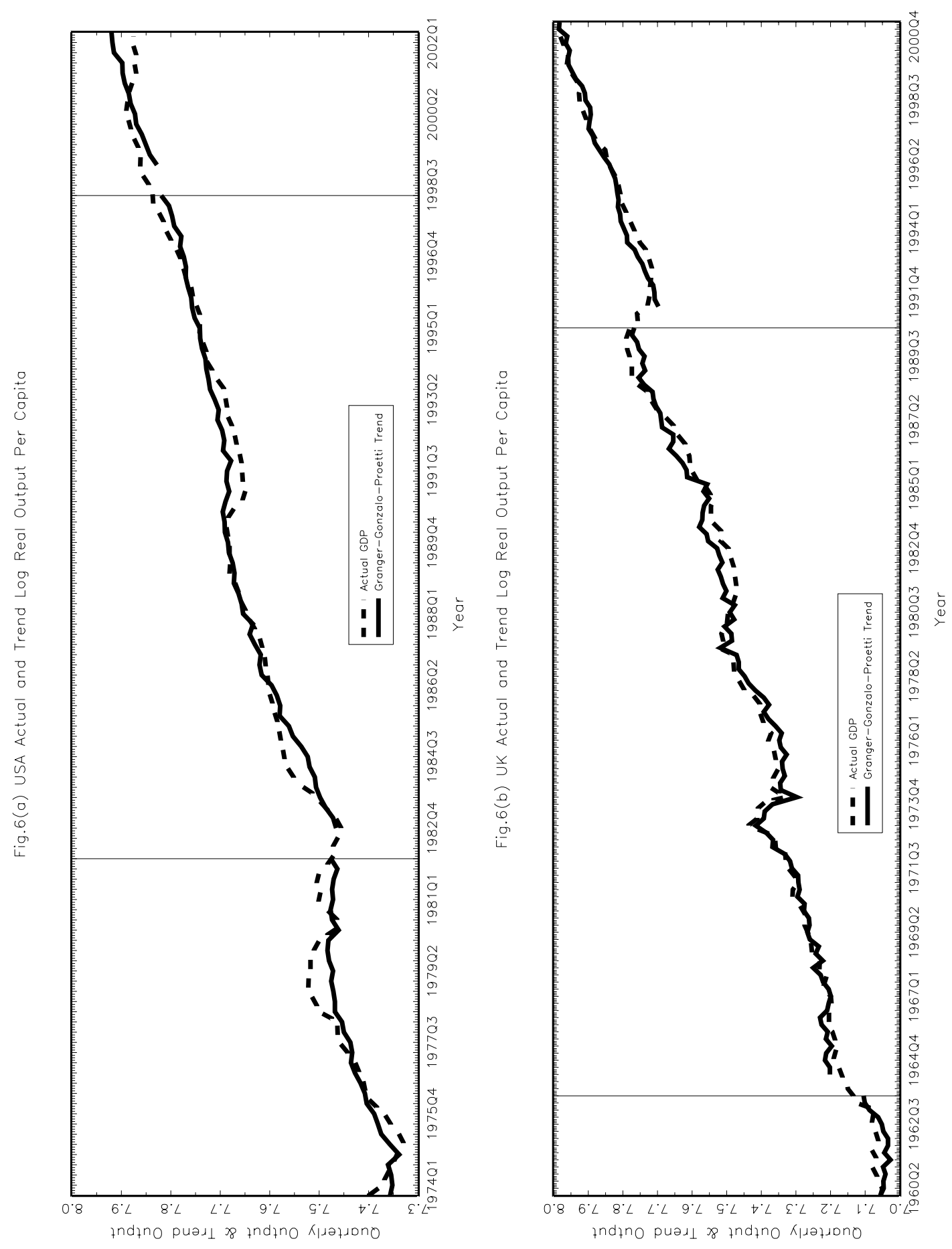

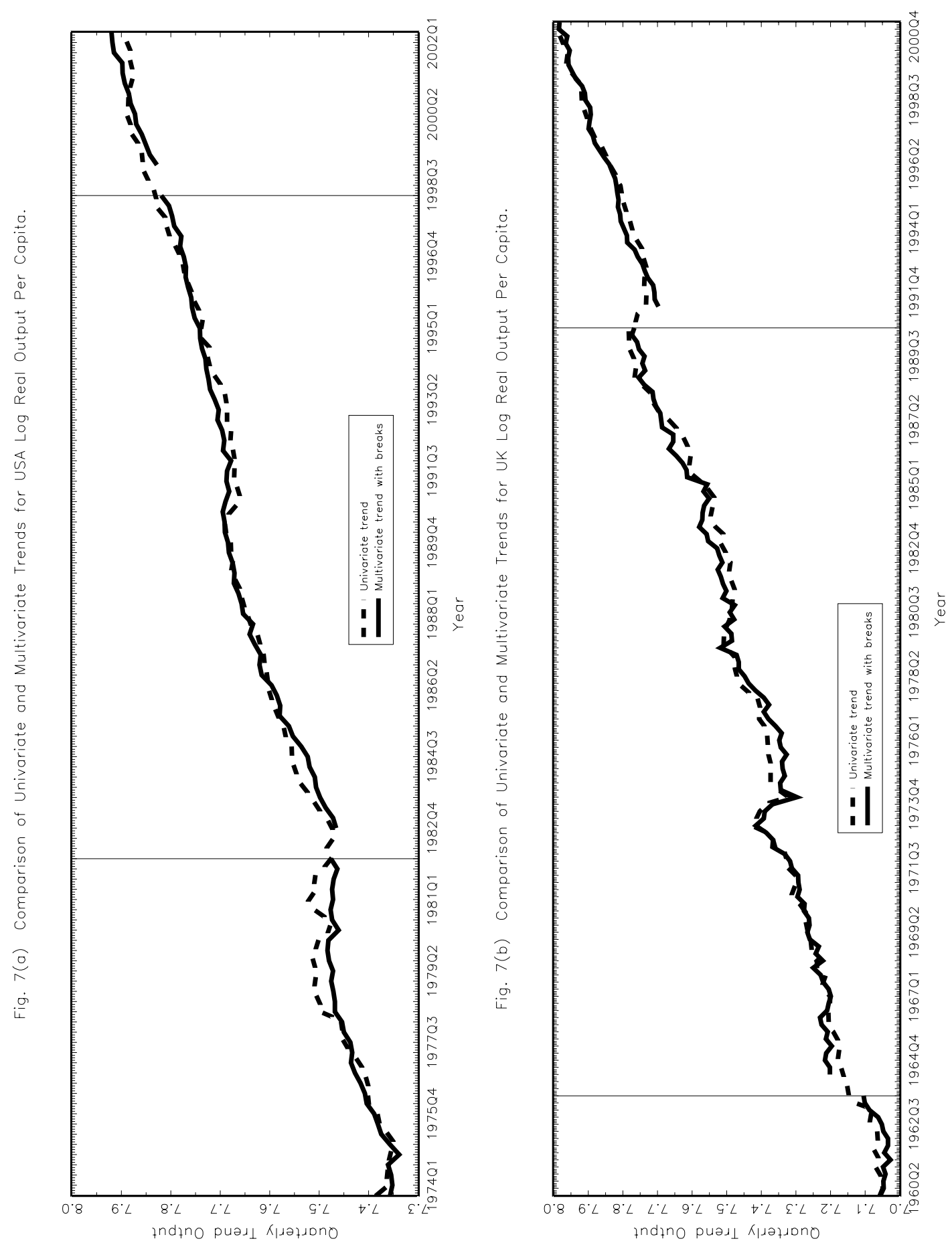